\title{
TRANSPORT AND DEPOSITION OF AIRBORNE FISSION PRODUCTS IN CONTAINMENT SYSTEMS OF WATER COOLED REACTORS FOLLOWING POSTULATED ACCIDENTS
}

\section{Battelle}

Pacific Northwest Laboratories Richland, Washington 99352

\section{JUNE 1974}




\section{DISCLAIMER}

This report was prepared as an account of work sponsored by an agency of the United States Government. Neither the United States Government nor any agency Thereof, nor any of their employees, makes any warranty, express or implied, or assumes any legal liability or responsibility for the accuracy, completeness, or usefulness of any information, apparatus, product, or process disclosed, or represents that its use would not infringe privately owned rights. Reference herein to any specific commercial product, process, or service by trade name, trademark, manufacturer, or otherwise does not necessarily constitute or imply its endorsement, recommendation, or favoring by the United States Government or any agency thereof. The views and opinions of authors expressed herein do not necessarily state or reflect those of the United States Government or any agency thereof. 


\section{DISCLAIMER}

Portions of this document may be illegible in electronic image products. Images are produced from the best available original document. 
NOTICE

The report was prepared as an account of work sponsored by the United States Government. Neither the United States nor the United States Atomic Energy Commission, nor any of their employees, nor any of their contractors, subcontractors, or their employees, makes any warranty, express or implied, or assumes any legal liability or responsibility for the accuracy, completeness or usefulness of any information. apparatus, product or process disclosed, or represents that its use would not infringe privately owned rights.

\author{
PACIFIC NORTHWEST LABORATORY \\ operated by \\ BATTELLE \\ for the \\ U.S. ATOMIC ENERGY COMMISSION \\ Under Contract AT(45-1)-1830
}

\author{
Printed in the United States of America \\ Available from \\ National Technical Information Service \\ U.S. Department of Commerce \\ 5285 Port Royal Road \\ Springfield, Virginia 22151 \\ Price: Printed Copy $\$ 4.00$; Microfiche $\$ 1.45$
}


TRANSPORT AND DEPOSITION OF AIRBORNE

FISSION PRODUCTS IN CONTAINMENT SYSTEMS

OF WATER COOLED REACTORS

FOLLOWING POSTULATED ACCIDENTS

by

P. C. Owzarski, A. K. Postma, and D. L. Lessor

June 1974

Thls repurt wOTICE

This repurt was prepared as an account of work

sponsored by the United States Government. Neither

the United States nor the IInited States Atomic Energy

Commission, nor any of their employees, nor any of

their contractors, subcontractors, or their employees,

makes any warranty, express or implied, or assumes any

legal liability or responsibility for the accuracy, com-

pleteness or usefulness of any information, apparatus,

product or process disclosed, or represents that its use
wound

would not infringe privately owned rights.

BATTELLE

PACIFIC NORTHWEST LABORATORIES

RICHLAND, WASHINGTON 99352 


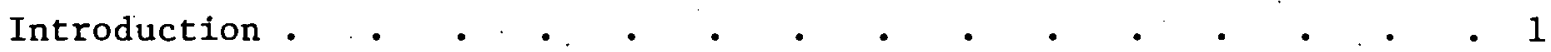

Mechanisms Which Control the Removal of Airborne Fission Products from Containment Atmospheres

Physical and Chemical Forms of Airborne Fission Products . . 1

Mechanisms Expected to Control Depletion from the Gas Phase . . . 2

Numerical Evaluation of Removal Rates . • • • . . . . . . . 4

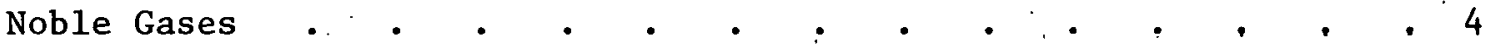

Methyl Iodide . . • . . . • . . . . . . . 4

Elemental Iodine." • • • • • • . . • • . . . . : 5

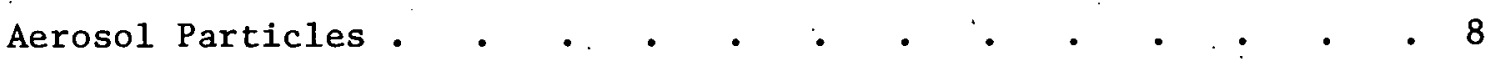

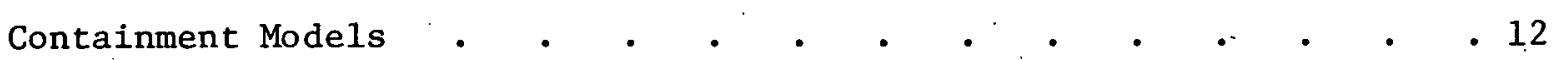

Single Volume Containment Model • • • • • . • . . 12

Multicompartment Containment Model - PWR . . . . . . . . 14

Multicompartment Containment Model - BWR . . . . . . . 22

Computer Code CORRAL . . . . . . . . . . . . . . . 31

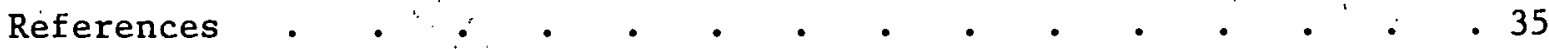


TRANS PORT AND DE POS ITION OF AIRBORNE FISS ION PRODUCTS IN CONTAINMENT SYSTEMS OF WATER COOLED REACTORS FOLLOWING POSTULATED ACCIDENTS

P. C. Owzarski, A. K. Postma, and $D$. L. Lessor Battelle

Pacific Northwest Laboratories

\section{Introduction}

In this report, fission product transport and deposition in containment systems of water cooled reactors is analyzed. The scope of the work involves prediction of fission product behavior from the point of release from the primary coolant system to the entry to the earth's atmosphere.

This study is one element in the Fission Product Source Term Task of the USAEC Reactor Safety Study. The goal of the Reactor Safety Study is to realistically evaluate the risk to the public of postulated catastrophic arridents in water cooled nuclear reactors.

This report contains a description of removal mechanisms which will deplete fission products airborne in containment systems, a listing of the calculational methods used to predict removal rates, and a description of a computer code for calculating atmospheric release of airborne substances from a multicompartmented containment system.

Mechanisms Which Control the Removal of Airborne Fission Products from Containment $\triangle$ tmospheres

$\underline{\text { Physical and Chemical Forms of Airborne Fission Products }}$

The mechanisms which control depletion of a specific fission product specie depend on its physical and chemical form. For example, gaseous fission product forms such as noble gases, organic lodides and elemental iodine are removed at. widely different rates because of great differences 
in equilibrium solubility in water. Except for the noble gases and halogens, fission products will be present as solid particles.

following:

Fission product formo conildered In the present study include the

- elemental lodine

- methyl iodide

- noble gases

- aerosol particles.

These categories are expected to be sufficiently broad to include all fission products of importance.

Mechanisms Expected to Control Depletion from the

Gas Phase

Noble Gases. For the accident cases considered, no removal mechanisms of importance were present. Therefore, removal of noble gases from the gas phase was considered to be negligible. It is recognized that several means for collecting noble gases have been proposed. These include clathrate compound formation, trapping by surface active agents such as refrigerated charcoal, separation by selective membranes, and absorption by fluorocarbon solvents. If any of these processes were considered operable following postulated accidents, a removal term would be added to the present formulations.

Methy1 Indide. Methyl iodide and other alkyl halldes are relatively unreactive and are only slightly soluble in water. Organic iodides are removed by hydrolysis in water, by adsorption on special reactive paints, by solution reaction with reactive spray additives such as sodium thiosulfate, and by activated charcoal filters.

For accident cases where engineered safety systems do not function, removal will be governed by hydrolysis in water and by adsorption on paint. The removal rate due to both of these mechanisms is slow, being equivalent to a removal half-time of many hours. Thus methyl iodide removal may be neglected for these accident cases.

Removal of methyl iodide by both caustic and boric acid spray is primarily by hydrolysis of methyl iodide in the spray solution. This hydrolys is rate is slow, and, like the case for no spray, the removal rate is usually negligible.

Addition of 1 percent by weight of sodium thiosulfate to the spray solution markedly increases the methyl iodide removal rate compared to that for boric acid or caustic spray. For the thiosulfate spray, methyl iodide.

*The discussion here is oriented mainly towards PWR systems but portions apply also to BWR systems. These plus additional BWR processes are described later in the report. 
removal is the result of absorption with simultaneous chemical reaction into wall films and into falling spray drops.

Activated charcoal filters such as those used in a recirculating air cleaning system remove methyl iodide at appreciable efficiencies. For the saturated air-steam atmospheres encountered under accident conditions in PWR's, removal efficiencies in the neighborhood of 70 percent are anticipated. Thus the removal rate will depend primarily on the air flow rate through the filters.

Elementa1 lodine. Elemental iodine is reactive in aqueous solution and may be rapidly absorbed by sprays. The absorption rate for boric acid is limited by the gas-liquid equilibrium partition coefficient. For caustic sprays the absorption rate is controlled more by gas phase mass transfer resistance than by equilibrium. "Liquid phase mass transfer resistance is negligible for sprays containing 1 percent by weight of sodium thiosulfate.

Activated charcoal filters are quite efficient for removal of elemental iodine. A removal efficiency of 99 percent could be expected for a charcoal filter installed in a recirculating filter loop. The removal rate would be controlled primarily by the air flow rates.

Elemental iodine is also removed by natural processes if engineered safety systems do not work. The removal rate may be estimated from models in which iodine mass transfer is limited by diffusion through a gas boundary. layer which flows along the walls of the containment vessel. Mass transfer coefficients for the natural convection boundary layer are relatively small, so the removal rate by natural deposition is small compared to that which can be achieved by reactive sprays.

Aerosol Particles. All non-gaseous fission products which become airborne will bc preesnt in the form of aernsol particles. Due to the relatively high mass concentration of airborne particles, the particles will consist of numerous primary nuclei agglomerated into larger particles. The agglomerate particles would be expected to contain primary particles of the many fission product nuclides present. Thus it is expected that the transport characteristics of all solid fission products would follow the behavior of the aerosol particles.

Particles may be removed by sprays, by filters; by deposition onto surfaces, and by gravitational settiing.

Mechanisms which cause collection of particles by spray drops include inertial impaction, interception, diffusiophoresis, and diffusion. Prediction of the collection rate requires knowledge of the single drop collection efficiency. In the present study, the single drop collection efficiency. was calculated from large scale spray experiments in which particle removal was measured under simulated accident conditions. This means for estimating the collection efficiency is expected to result in an 
under-prediction, because in the postulated accidents higher aerosol concentrations favor formation of larger, easier-to-remove particles.

Particulate filters used in recirculating filter systems are highly efficient in removing airborne particles of all sizes. Therefore, recirculating filters systems, if included in a containment system design, could be relied on to remove more than 99 percent of airborne particles per pass.

Under natural transport conditions, gravity settling of particles on horizontal surfaces, and turbulent deposition on vertical surfaces represent the primary removal mechanisms. Experiments have demonstrated that gravity settling will dominate in the post accident containment atmosphere. In the present study, the particle gravity settling velocity, and hence the aerodynamic diameter, were obtained from experimental data obtained in large scale containment vessels.

\section{Numerical Evaluation of Remova1 Rates}

\section{Noble Gases}

For the accident cases which have been studied to date, no specific means have been included to remove noble gases. Since these gases would not be removed to a significant extent by sprays, filters, or natural deposition, the removal rate from the total. system has been set equal to zero. Removal from a specific compartment of the containment vessel may occur by convective flow of gas, but this output term would represent an input term to the connected compartment.

\section{Methy 1 Iodide}

Methyl iodide is removed only very slowly under conditions of natural deposition or where sprays of boric acid or caustic are used. Removal half-times are many hours for these three cases, hence methyl iodide removal may be neglected without excessive error.

Appreciable removal of methyl iodide would occur if a recirculating charcoal filter system were incorporated in the containment system. Results obtained in the Containment Systems Experiment (1) have demonstrated that a removal efficiency of approximately 80 percent is achieved for methyl iodide when saturated steam-air atmospheres pass through charcoal filters impregnated with 5 percent iodine. The removal rate constant for such a filter system may be expressed as

$$
\left(\frac{d c}{d t}\right)_{f}=\lambda_{f} c=\frac{F E}{V} c
$$

where

$$
\begin{aligned}
\left(\frac{\mathrm{dC}}{\mathrm{dt}}\right)_{\mathrm{f}} & =\text { removal rate due to filter system, } \\
\lambda_{\mathrm{f}} & =\text { removal rate constant for filter system, }
\end{aligned}
$$




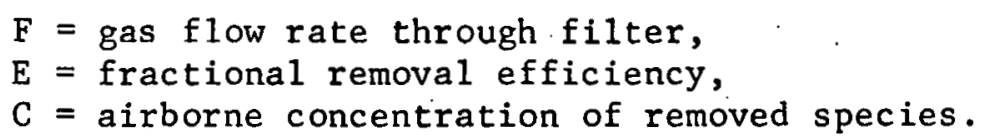

Based on the CSE tests, E should be chosen as 0.8 for methyl iodide, and equal to 1.0 for both elemental iodine and aerosol particles.

Methyl iodide is removed at an appreciable rate by sprays containing sodium thiosulfate at a level of one weight percent. The removal rate constant for reactive drops may be predicted (2) by

$$
\lambda_{\text {drops }}=\frac{F H\left(1+k t_{e}\right)}{V}
$$

where

$$
\begin{aligned}
\lambda_{\mathrm{drops}} & =\text { methyl iodide removal by spray drops, } \\
\mathrm{F} & =\text { spray flow rate, } \\
\mathrm{V} & =\text { volume of contained gas phase, } \\
\mathrm{H} & =\text { equilibrium partition coefficient } \\
\mathrm{k} & =\text { first order solution reaction rate } \\
t_{e} & =\text { drop exposure time. }
\end{aligned}
$$

This equation applies for a we 11 mixed drop model, and is expected to realistically represent the situation prevailing for containment sprays.

In addition to removal by spray drops, methyl iodide will also be removed by spray liquid which has wet the wall of the containment vessel. If the wall film is assumed to be stagnant, the methyl iodide absorption rate is given by

where

$$
\lambda_{(\text {wa } 11)}=\frac{\mathrm{AH} \sqrt{\mathrm{kD}} \tanh [\sqrt{(\mathrm{k} / \mathrm{D}) \delta]}}{\mathrm{V}}
$$

$$
\begin{aligned}
\lambda(\text { wa11) } & =\text { removal rate constant for wall film, } \\
\mathrm{A} & =\text { surface area wet by wall film, } \\
\mathrm{H} & =\text { equilibrium partition coefficient, } \\
\mathrm{D} & =\text { diffusivity of methy lodide in spray liquid, } \\
\delta & =\text { wall film thickness, } \\
\mathrm{V} & =\text { volume of contained gases. }
\end{aligned}
$$

The net removal rate will be the sum of that for wall film and spray drops:

$$
\lambda=\frac{F H\left(1+k t_{e}\right)}{V}+\frac{A H \sqrt{k D} \tanh (\sqrt{(k / D)} \delta)}{V}
$$

Predictions based on equation (4) are in good agreement with large scale experiments. (2)

\section{Elemental Iodine}

Elemental iodine is removed by natural deposition at a rate which is controlled by mass transfer through the gas boundary layer at the walls 
of the containment vesse1. The natural deposition removal rate constant is simply

where

$$
\lambda_{(\mathrm{NT})}=\frac{\mathrm{k}_{\mathrm{g}} \mathrm{A}}{\mathrm{V}}
$$

$$
\begin{aligned}
\lambda(\mathrm{NT}) & =\text { removal rate constant for natural deposition, } \\
\mathrm{A} & =\text { surface area for mass transfer, } \\
\mathrm{V} & =\text { volume of contained gases. }
\end{aligned}
$$

Knudsen and Hilliard (3) have discussed methods for calculating $\mathrm{k}_{\mathrm{g}}$ for containment vessels. The value of $\mathrm{kg}_{\mathrm{g}}$ is governed primarily by the Grashov number for natural convection. For laminar flow, the mass transfer coefficient is given by

$$
\frac{\mathrm{k}_{\mathrm{c}} l}{\mathrm{D}_{\mathrm{v}}}=0.59(\mathrm{Gr} \mathrm{Sc})^{1 / 4}
$$

where

$$
\begin{aligned}
\mathrm{k}_{c} & =\text { mass transfer coefficient, } \\
d & =\text { length along surface, } \\
\mathrm{D}_{\mathrm{v}} & =\text { diffusivity of iodine in gas phase, } \\
\mathrm{Gr} & =\text { Grashov no. for wall boundary layer } \\
\mathrm{Sc} & =\mathrm{S} \text { chmidt no. for iodine in steam. }
\end{aligned}
$$

For turbulent flow

$$
\frac{k_{c} l}{D_{v}}=0.13(G r S c)^{1 / 3}
$$

Lauinar flow peraioto until the Grashov number exxceeds a trans ition value. According to an analys is presented by Hales (4) transition from laminar to turbulent flow occurs for lengths which correspond to Grashov numbers between $1.5 \times 10^{8}$ and $1.5 \times 1010$. For containment atmospheres, this transition would occur at distances 5 to $10 \mathrm{ft}$ down the vertical wall. (5) Thus Equation (6) would apply for the first $10 \mathrm{ft}$, and Equation (7) would apply for the remainder of the distance.

Hilliard and Coleman(5) have provided estimates of iodine remuval by natural deposition based on use of Equations (6) and (7). The airborne concentration is predicted to be.

where

$$
\frac{C_{g}}{C_{g 0}}=0.96 e^{-1.42 t}+0.04 e^{-0.0143 t}
$$

$$
\begin{aligned}
\mathrm{C}_{g} & =\text { airborne concentration, } \\
\mathrm{C}_{\mathrm{go}} & =\text { airborne concentration at time zero, } \\
\mathrm{t} & =\text { time in hours. }
\end{aligned}
$$

The first term in Equation (8) represents removal by mass transfer through the wall boundary layer. The second term accounts for an approach to 
pseudo-equilibrium between the gas and liquid phases. The initial removal half life for a large vessel as predicted by Equation (8) is approximately 30 minutes.

For spray removal of elemental iodine, the removal rate may be predicted from a model in which the spray is considered to be an assemblage of noninteracting single drops. The overall drop. absorption process includes the following steps:

- mass transfer across the gas film

- equilibrium dissolution at the gas-liquid interface

- diffusion into the drop

- reaction within the liquid phase.

A conseravtive model for spray absorption may be formulated under the assumption that the drop consists of an outer stagnant film and a wellmixed interior. For this model, the absorption efficiency (defined as fractional saturation achieved by a drop falling through the containment vessel) is given by

$$
E=1-\exp -\left[\frac{6 k_{g} t_{e}}{d\left(H+\frac{k_{g}}{k_{L}}\right)}\right]
$$

where

$$
\begin{aligned}
E & =\text { drop absorption efficiency, } \\
k_{g} & =\frac{D}{d}\left(2+0.6 \mathrm{Re}^{0.5} \mathrm{sc}^{0.33}\right)=\text { gas phase mass transfer coef., } \\
k_{L} & =\frac{2 \cdot \pi^{2} D_{L}}{3 d}=1 \text { iquid phase mass transfer coefficient, } \\
t_{e} & =\text { drop exposure time, } \\
H & =\text { equilibrium partition coefficient. }
\end{aligned}
$$

The basis and assumptions involved in formulating equation (9) are discussed in detail by Postma and Pasedag. (6).

The spray removal rate constant may be related to the spray flow rate and drop absorption efficiency by

where

$$
\lambda_{s}=\frac{F H E}{V}
$$

$$
\begin{aligned}
\lambda_{S} & =\text { spray removal rate constant, } \\
H & =\text { equilibrium partition coefficient, } \\
E & =\text { drop absorption efficiency, } \\
V & =\text { volume of contained gas. }
\end{aligned}
$$

The partition coefficient appearing in Equations (9) and (10) is the value attained in a few seconds. This time specification is necessary because iodine dissolution is greatly influenced by chemical reactions. Only those reactions which are fast enough to convert elemental iodine to non-volatile forms within a time period shorter than the drop exposure time will aid spray absorption. 
On the basis of available information, Postma and Pasedag(6) have concluded that applicable $\mathrm{H}$ values are as follows:

- for caustic, $\mathrm{pH} 9.5, \mathrm{H}=5000$

- for boric acid, $\mathrm{pH}=5, \mathrm{H}=200$

- for basic sodium thiosulfate, $\mathrm{H}=100,000$.

The first order removal rate predicted by Equation (10) will not continue to apply for an indefinite time because of equilibrium between the gas and liquid phase. For the first two hours following spray initiation, equilibrium may be accounted for by limiting spray removal to 1 percent of the release concentration. (6) Beyond the time needed to remove 99 percent of airborne iodine, the concentration should be assumed to remain constant at 1 percent of the release concentration.

For times longer than two hours, the gas concentration may be allowed to decrease further as a resull uf cliemical reactions in the liquid phase. For equilibrium conditions, which would be attained for times longer than a few hours, the airborne iodine concentration is given by

where

$$
\frac{\mathrm{C}_{\mathrm{g}}}{\mathrm{C}_{\mathrm{go}}}=\frac{1}{1+\mathrm{H} \frac{\mathrm{V}}{\mathrm{V}_{\mathrm{g}}}}
$$

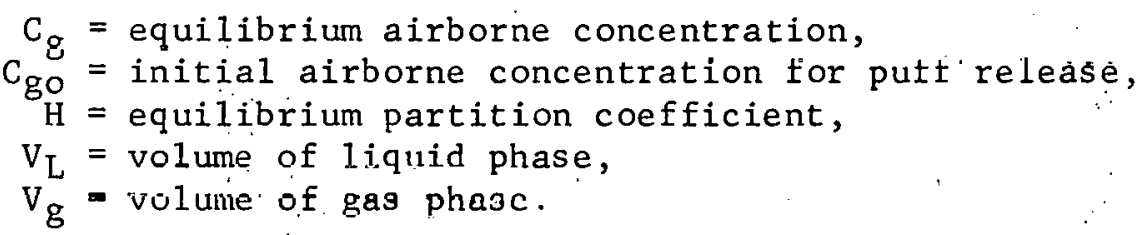

The partition coefficient, $H$, in Equation (11) increases with time due to kinetically slow liquid phase reactions. In this study, the variation of $\mathrm{H}$ with time was taken from experimental results reported by Postma, et al. (7) Experimental results for caustic and boric acid snlutions are shown in Figure. 1. The data presented in Figure 1. were used to conjunction with Equation (11) to predict long term behavior of elemental iodine in caustic and boric acid spray.

For spray containing 1 percent sodium thiosulfate, partilion coefficients will be large. As discuesed by Pustima and Fasedag, (6) the cutoff concentration for sodium thiosulfate sprays may be taken as 0.1 percent of the release concentration.

Aerosol Particles

Particles are removed by natural transport primarily by gravitational settling. (5). The removal rate constant is related to the particle settling velocity by.

$$
\lambda=\frac{U_{t} A_{c s}}{V}
$$




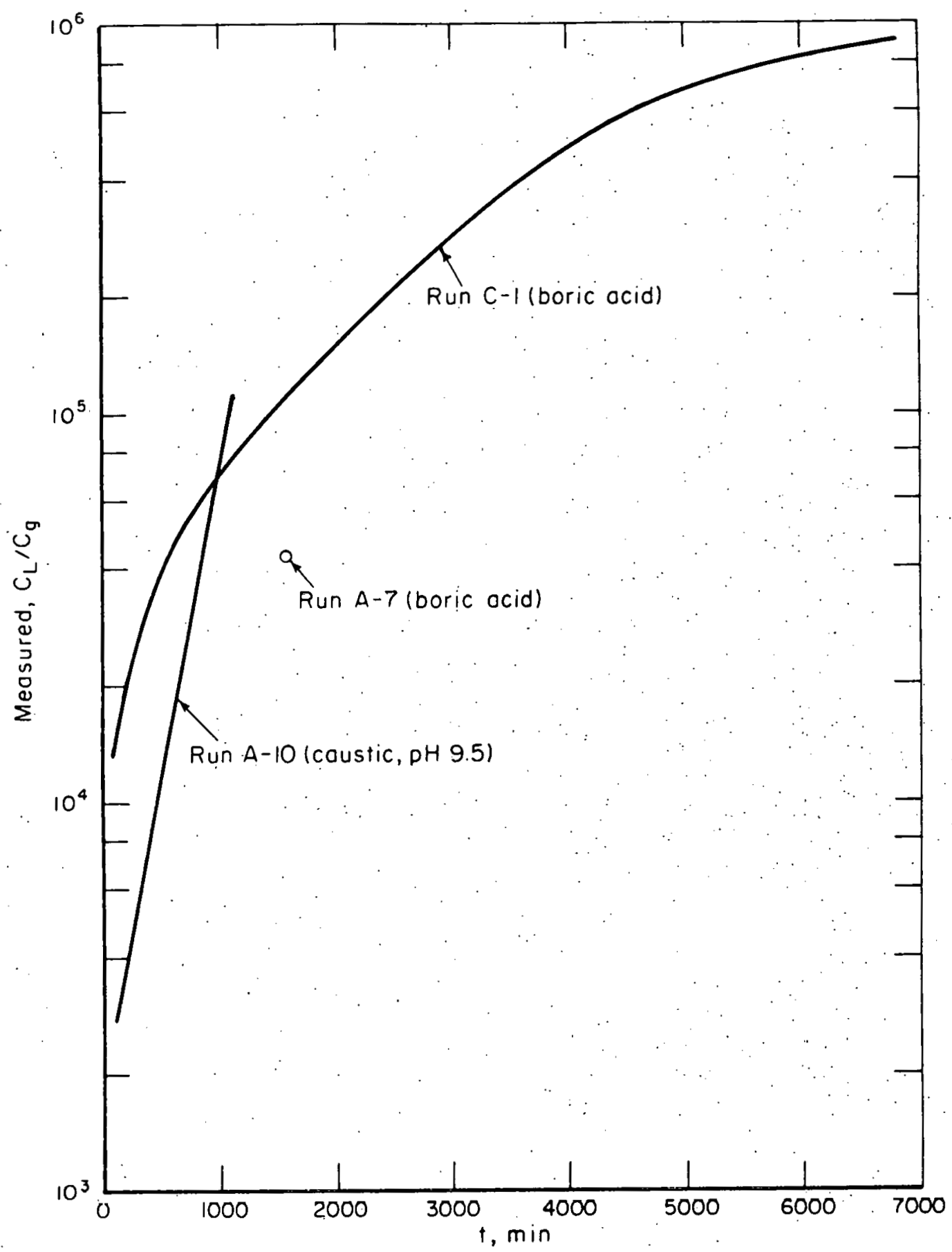

FIGURE 1. PAR TITIONING OF ELEMENTAL IODINE BY RECIRCULATED.SPRAYS

Results of runs in the CSE.

$C_{g}$ is for elemental iodine. 
where

$$
\begin{aligned}
\lambda & =\text { removal constant for settling, } \\
\mathrm{A}_{\mathrm{CS}} & =\text { cross sectional area of vessel, } \\
\mathrm{V} & =\text { volume of contained gases, } \\
U_{\mathrm{t}} & =\text { terminal settling velocity of particles. }
\end{aligned}
$$

Results from CSE experiments(5) indicate that soon after fission product release, particle diameter was 8 microns. A few hours later; average particle size decreased to about 3 microns.

The CSE results indicate that aerosol particles will be removed slowly by natural processes. Because of higher aerosol mass concentrations in postulated core meltdown accidents, the C'SE results will tend to underpredict removal for the meltdown accidents. We have not attempted to account for this difference in the present study:

For recirculating filter systems, particle removal would be described by Equation (1) with an efficiency fraction of unity.

Spray removal of aerosol particles may be predicted from a model in which the spray is considered to be an assemblage of non-interacting single drops. The overall removal rate is the sum of removal rates for individual drops. For a well-mixed gas space, the removal rate constant is expressible as

$$
\lambda=\frac{3 h \mathrm{hE}}{2 \mathrm{dV}}
$$

where

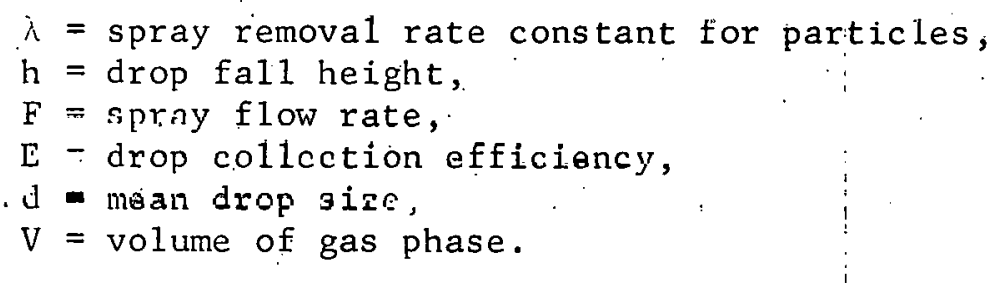

The magnitude of the drop collection efficiency, E, depends on a number of factors as discussed earlier. Particle size of the aerosol is the most important single parameter, and size was estimated from CSE spray experiments.

In applicable CSE tests (8) the effective particle collection efficiency varied from a maximum value $(E=0.6)$ achieved early to a mini. mum value (E - 0.0015) redulied after most of the ncroool was removed. In single volume, hand calculation models an average value of 0.02 may be used. After the airborne concentration reduces to 2 percent of the release concentration, the drop collection efficiency used in the calculation should be lowered to 0.0015 . In multicompartment containment models, E should be allowed to vary with the degree of removal as was ubserved in the CSE experiments.

Examples of removal rates calculated for a large PWR contalnment vessel are shown in Table 1 . These values were used in preliminary hand calculations with a single volume containment model. 
TABLE 1. FISSION PRODUCT REMOVAL RATE CONSTANTS

CALCULATED FOR A LARGE PWR CONTAINMENT VESSEL

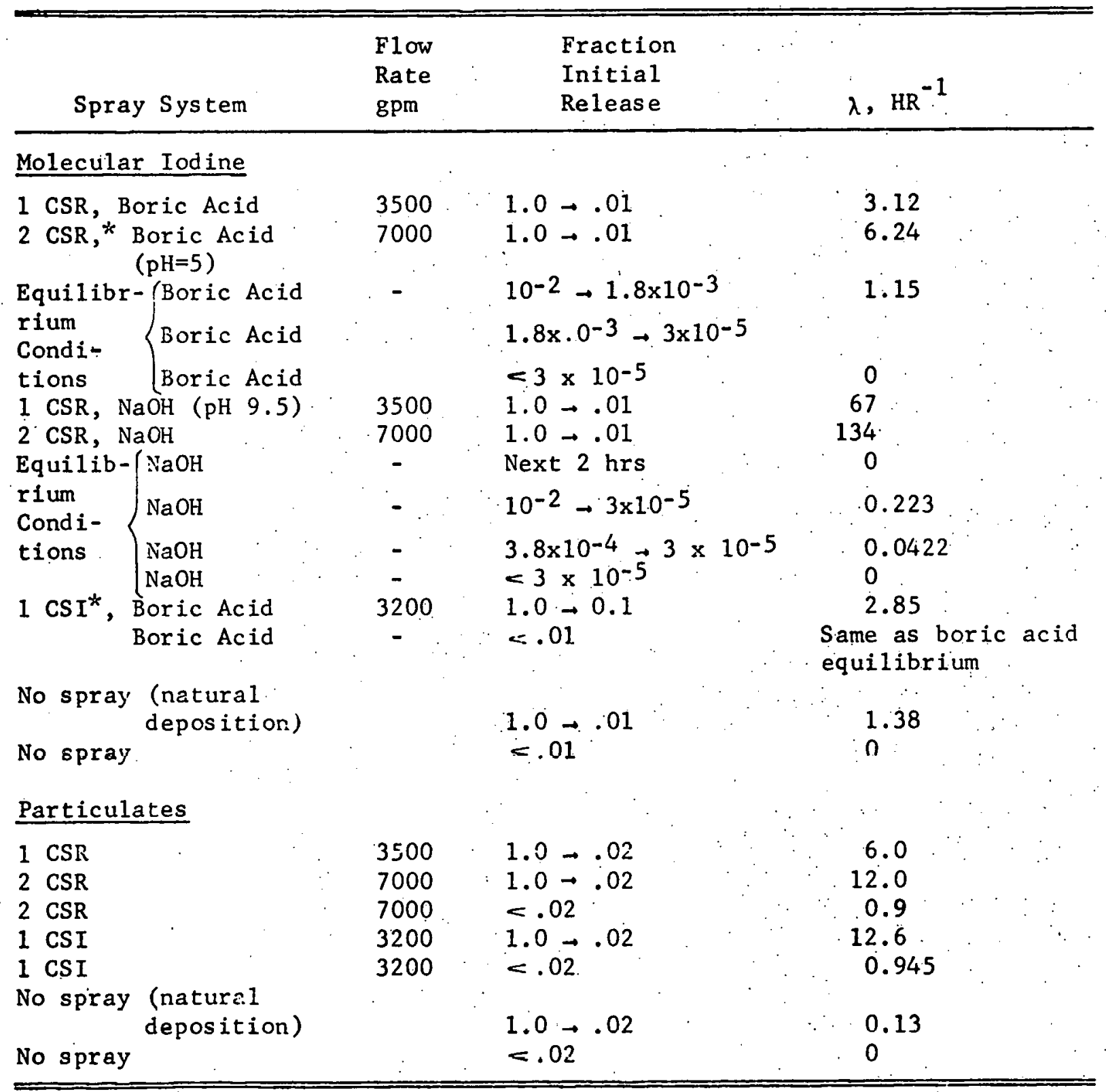

*CSR = Recirculation spray.. CSI = Injection Spray. 


\section{Containment Models}

Single Volume Containment Model

The single volume containment model assumes that the vapor phase consists of one well-mixed compartment. This assumption enables one to write the following single differential equation for each species:

$$
\mathrm{d} \frac{\mathrm{C}_{i}}{\mathrm{dt}}=-\left(\sum \lambda_{i j}\right) \cdot \mathrm{C}_{i}-\alpha_{i} \mathrm{C}_{i}+\mathrm{R}_{i}(t)
$$

Initial Condition: $C_{i}=C_{i}\left(t^{\prime}\right)$ at $t=t^{\prime}$.

$C_{i}=$ Airborne moles of component $i$

$\lambda_{i j}=$ Removal rate constant via mechanism $j$

$\alpha_{i}=$ leak rate, fraction of the volume/time

$R_{i}(t)=$ source term (moles/time).

This equation is easily solved for constant $\lambda_{i j}, \alpha_{i}$ and $R_{i}$ to get

$$
c_{i}=\frac{R_{i}}{\left(\Sigma \lambda_{i j}+\alpha_{i}\right)}-\left[\frac{R_{i}}{\left(\Sigma \lambda_{i j}+\alpha_{i}\right)}-c_{i}\left(t^{\prime}\right)\right] \exp -\left(\Sigma \lambda_{i j}+\alpha_{i}\right)\left(t-t^{\prime}\right)
$$

The escaped amount during the interval $t-t^{\prime}$ is the integral

$$
\begin{gathered}
Q_{1}=\int_{t^{\prime}}^{t} C_{i} V \alpha_{i} d t \text {, where } V \text { is the volume of the vessel. Thus } \\
Q_{i}=\frac{R{ }_{i} V \alpha_{i}}{\left(\Sigma \lambda_{i j}+\alpha_{i}\right)} \cdot\left(t-t^{\prime}\right)-\left[\frac{R}{\left(\Sigma \lambda_{i j}+\alpha_{i}\right)}-C_{i}\left(t^{\prime}\right)\right]\left(\frac{\alpha_{i} V}{\Sigma \lambda_{i j}+\alpha_{i}}\right) \\
\quad \times\left(1-\exp \left[-\left(\Sigma \lambda_{1 j}+\alpha_{i}\right)\left(t-t^{\prime}\right)\right]\right.
\end{gathered}
$$

The two equations. for $C_{i}(t)$ and $Q_{i}\left(t-t^{\prime}\right)$ can be used to calculate airborne fractions and leakage tractions for various accident sequences by hand. The values of $\lambda_{i j}$, used for various species are discussed earlier in this report and sumarized in Table 1 . Typical curves describing the moles airborne and escaped are shown in Figures 2 and 3.

The only release of fission products encountered where $R_{i}=$ constant for some time period is the melt release. This simplifies most of the computations to using an initial condition for a time period where the $\lambda_{i j}$ 's and $\alpha_{i}$ 's are considered to be constant. If the $\lambda^{\prime} s$ or $\alpha^{\prime}$ 's changed at some time, $t^{\prime}$, a new $t^{\prime}$ can be considered as the beginning of a new time period of constant new $\lambda^{\prime} s$ or $\alpha^{\prime} s$. 


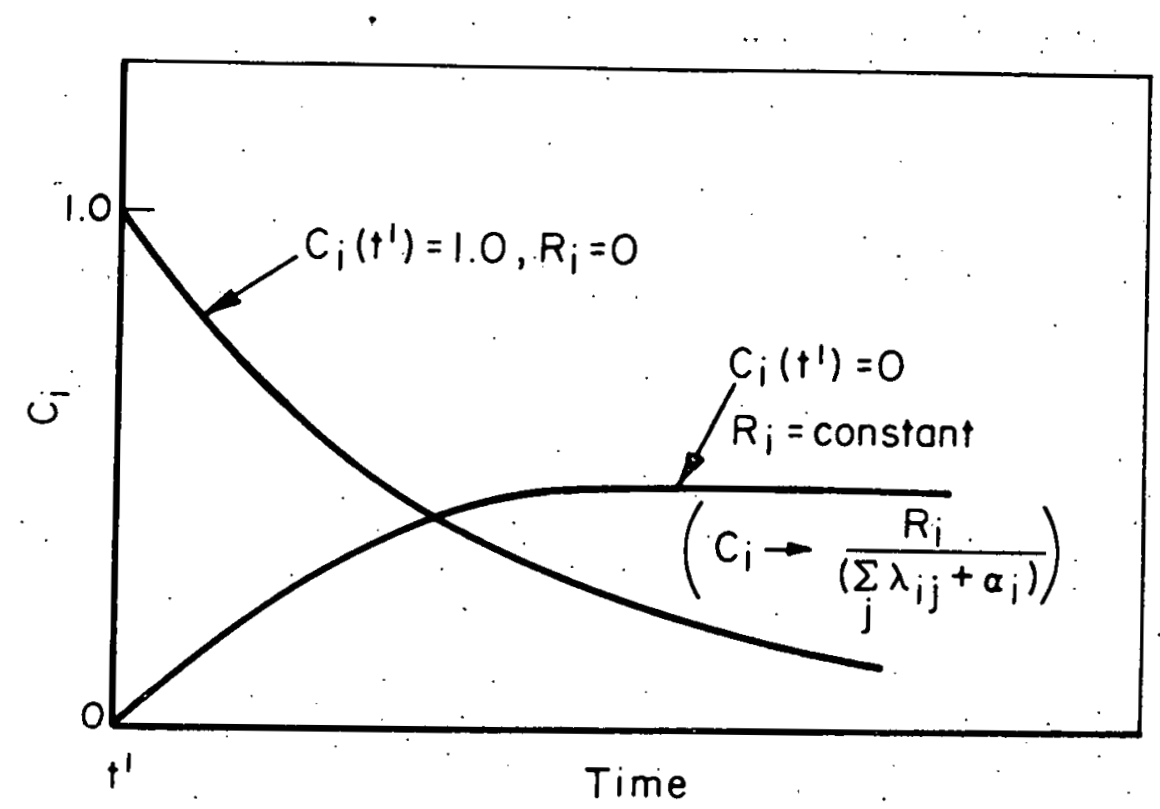

FIGURE ${ }^{\sim}$ 2. SCHEMATIC OF QUANTITY OF AIRBORNE-CON TAINED FISSION PRODUCTS VERSUS TIME

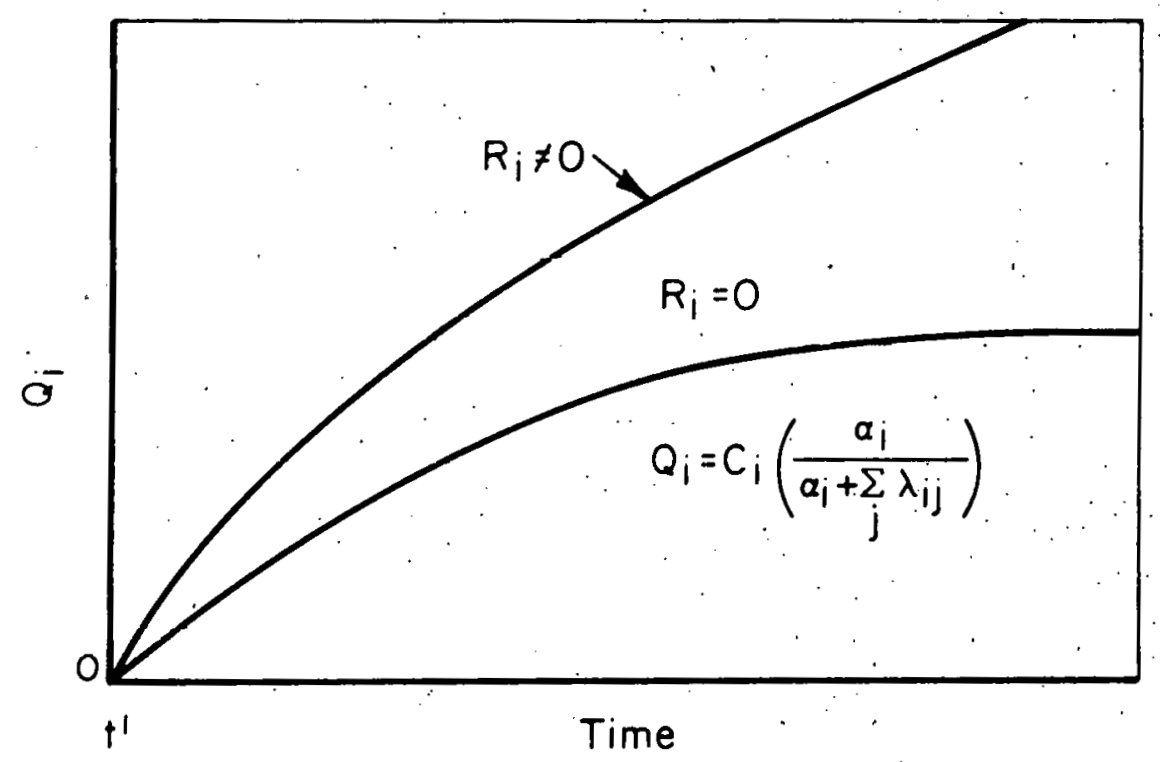

FIGURE' 3. SCHEMATIC OF QUAANTITY OF FISSION PRODUCTS RELEASED TO ATMOSTIIERES VERSUS TIME 
Multicompartment: Containment Model - PWR

To better simulate containment geometry and time variable removal rates, a model was cieveloped to analyze the atmospheric source from a set of compartments whose airborne contents are well mixed and are altered by intercompartmental flow in addition to deposition rates, leak rates, spray removal rates, etc. This system is described by a set of equations of the form

where

$$
\mathrm{dc}_{i}^{\mathrm{mr}} / \mathrm{dt}=\sum_{j} \mathrm{H}_{i j}^{\mathrm{mr}} \mathrm{c}_{j}^{\mathrm{mr}}
$$

$$
\begin{aligned}
& \begin{aligned}
C_{i}^{\mathrm{mr}}= & \text { airborne fraction of initial release of material } \mathrm{m} \\
& \text { in release type } r \text { contained in compartment } i
\end{aligned} \\
& H_{i j}^{m r}=\left(\lambda_{i}^{m r}+\sum_{k} G_{k i} / V_{k}\right) \delta_{i j}+\left(G_{j i} / V_{j}\right)\left(1-E_{j i}^{m r}\right) \\
& \lambda_{i}^{m r}=\text { removal coefficient from compartment } i \text { by settling, } \\
& \text { leak, spray removal, and other processes not involving } \\
& \text { flow to or from another compartment } \\
& G_{i}=\text { volume flow rate from compartment } j \text { to compartment } i \\
& E_{j i}^{\mathrm{mr}^{\mathrm{i}}}=\text { filter removal fraction for material } \mathrm{m} \text { from release } \\
& v_{j}=\text { volume of compartment } j \\
& \delta_{i j}=I \text { if } i=j, \delta_{i j}=0 \text { if } i \neq j
\end{aligned}
$$

Note that the flow terms assume uniform mixing within each compartment.

For a given release type and material type, the equation set can be written in matrix notation

$$
\frac{\mathrm{dC}}{\mathrm{dt}}=\mathrm{HC}
$$

Where $\mathrm{C}$ is the column vector of airborne release fractions in the respective compartments and $\mathrm{H}$ is the matrix of rate constants governing the evolution. The solution of this differential equation for the column vector $\mathrm{C}$ for constant coefficients in the $\mathrm{H}$ matrix is given exactly by

$$
c(t)=e^{H t} c(0)
$$

or

$$
c(t)=C\left(t_{0}\right)+\left(t-t_{0}\right) H\left(\frac{e^{\left(t-t_{0}\right) H}-1}{\left(t-t_{0}\right) H}\right) C\left(t_{0}\right):
$$

Fast computer techniques for generating this solucion have been developed by B. H. Duane (18) and were utilized here. By calling the numerical integration subroutines developed by. Duane at each time step after calculating the $H$ matrix, the accuracy limit becomes that imposed by the assumption of coistant $H$ matrix elements within the time step. Numerical. error in generaiting the solution to the coupled set of equations with constant coefficieits can be made oii the order of $10^{-6}$ percent. 
To integrate the amount leaked within the time step, $N$ additional fictitious compartments were defined whose function is to accumulate the " leaked material from the $\mathrm{N}$ real compartments. The fractions $\mathrm{C}_{i+\mathrm{N}}, i=1$, $2, \cdots N$, are cumulative leaks obtained from the solution of $\frac{d}{d t}\left(C_{i+N}\right)=$ $\alpha_{i} C_{i}$ where $\alpha_{i}$ is the leak rate coefficient from compartment $i$. Note $-\alpha_{i}$ is one part of $\mathrm{H}_{\mathrm{ii}}$. The previously defined $\mathrm{N} \times \mathrm{N} \mathrm{H}$ matrix was augmented to form a $2 \mathrm{~N} \times 2 \mathrm{~N} \mathrm{H}$ matrix according to

$$
\begin{array}{ll}
\mathrm{H}_{\mathrm{i}+\mathrm{N}, \mathrm{j}}=\alpha_{\mathrm{i}} \delta_{i j} & \\
\mathrm{H}_{\mathrm{i}, \mathrm{j} N \mathrm{~N}}=0 & \text { For } \mathrm{i}=1,2, \cdots, \mathrm{N}
\end{array}
$$$$
H_{i+N, j+N}=0 \quad j=1,2, \cdots, N
$$

If one takes the material quantity in the fictitious compartments to be zero at the start of a time step, the fraction of the initial: release material leaked during the time step will be

$$
\sum_{1=N}^{2 N} C_{1}
$$

Computer code CORRAL* was written to solve the set of equations and at the same time compute each rate parameter as a function of time and/or as a function of vessel conditions ( $P, T$, humidity). A more detailed description of the various models used to compute rate parameters follows.

Nine time dependent parameters are computed from input data at the time of solution of the differential equations. These are:

1. Compartment pressure, $p(k)$, psig

2. Compartuent teimp, $\mathrm{T}(\mathrm{k}), \mathrm{F}$

3. Compartment vapor mole fraction, $\operatorname{VAP}(k)$

4. Compartment wall-bulk temperature difference, DELTA $T(k), F$

5.-6. Leak rates of molecular iodine and particulates from each

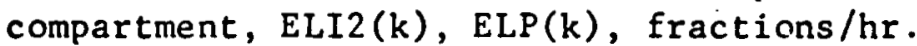

7. Flow rates between compartments, $G(j, k), \mathrm{ft}^{3} / \mathrm{hr}$.

8.-9. Filter decontamination efficiencies for flow between compartments, EFI2( $J, K O, \operatorname{EFP}(j, k)$, dimensionless.

The flrst four parameters enable one to compute transport coefficients Involved in depletion rate coefficient calculations.

The bulk gas viscosities of steam-air mixtures $\left(\mu_{m}\right)$ are computed according to the frillowing equations:(19)

*Containment of Radionuclides Released After. LOCA. 


$$
\mu_{m}=\frac{\mu_{A}}{1+\frac{y_{S}}{y_{a}} \phi_{A S}}+\frac{u_{S}}{1+\frac{y_{A}}{y_{s}} \phi_{S A}}
$$

where

$$
\begin{aligned}
& \mu_{m}=\text { viscosity of mixture } \\
& \mu_{A}=0.0414\left[\frac{T, R}{4.92}\right]^{0.768}, 1 \mathrm{~b} / \mathrm{ft} / \mathrm{hr} \\
& \mu_{S}=\frac{0.003339(T, R)^{1.5}}{\left(T_{R}+1224.2\right)} \\
& \mathrm{y}_{\mathrm{A}}=\text { mole fraction of air } \\
& y_{s}=\text { mole fraction of steam } \\
& b_{\mathrm{As}}=\frac{\left[1+\left(\frac{\mu_{\mathrm{A}}}{\mu_{\mathrm{S}}}\right)^{1 / 2}\left(\frac{\mu_{\mathrm{S}}}{\mu_{\mathrm{A}}}\right)^{1 / 4}\right]^{2}}{2 \pi\left[1+\left(\frac{\mu_{\mathrm{A}}}{\mu_{\mathrm{S}}}\right)\right]^{1 / 2}} \\
& \phi_{s A}=\text { above, with subscripts reversed. }
\end{aligned}
$$
data and equations from Knudsen. (19).

$$
\mathrm{D}_{\mathrm{I}_{2}}=\frac{1}{\frac{\mathrm{y}_{\mathrm{A}}}{\mathrm{D}_{\mathrm{A}}}+\frac{\mathrm{y}_{\mathrm{s}}}{\mathrm{D}_{\mathrm{s}}}}
$$

where

$$
\begin{aligned}
& \mathrm{D}_{\mathrm{A}}=2.03 \times 10^{-5}(\mathrm{~T}, \mathrm{~K})^{1.5} /(\mathrm{P}, \mathrm{atm}) / \mathrm{W}_{\mathrm{A}}, \mathrm{cm}^{2} / \mathrm{sec} \\
& \mathrm{D}_{B}=3.24 \times 10^{-5}(\mathrm{~T}, \mathrm{~K})^{1.5} /(\mathrm{P}, \text { atm }) / \mathrm{W}_{\mathrm{S}} \\
& \mathrm{W}_{\mathrm{A}}=0.7075+141.73 / \mathrm{T}, \mathrm{K} \\
& \mathrm{W}_{\mathrm{S}}=0.7075+454.72 / \mathrm{T}, \mathrm{K}
\end{aligned}
$$

The diffusivity of. $I_{2}$ in water (spray drops) was computed using the standard. Wilke-Chang relationsh1p. (10), where

$$
n_{i}=\frac{\left(7.4 \times 10^{-8}\right)\left(\mathrm{xM}_{\ell}\right)^{1 / 2} \mathrm{~T}(\mathrm{~K})}{\mu_{\mathrm{L}} \mathrm{v}^{0.6}} ; \mathrm{cm}^{2} / \mathrm{sec}
$$


where

$$
\begin{aligned}
x= & \text { degree of solvent association }=2.6 \text { for } \mathrm{H}_{2} \mathrm{O} . \\
M_{\ell}= & \text { molecular weight of solvent } \\
\mu_{\mathrm{L}}= & \text { solvent viscosity, cp } \\
\mu_{\mathrm{L}}= & 100 /\left\{2.1484\left[(\mathrm{~T},(\mathrm{~K})-281.6)+\left(8078.4+(\mathrm{T},(\mathrm{K})-281.6)^{2}\right)^{0.5}\right] .\right. \\
& -120\} \text { for } \mathrm{H}_{2} \mathrm{O} \\
\mathrm{V}= & \text { molar volume of diffusing substance }=71.5 \mathrm{~cm}^{3} / \text { gmole for } \mathrm{I}_{2} .
\end{aligned}
$$

Natural Deposition. The mechanism of natural deposition of $I_{2}$ is governed by diffusion with natural convection generated by temperature differences between bulk gas and the wall (DELTAT(k)). Knudsen and Hilliard(3) claim that a mass transfer analogy can be made with correlations predicting natural convective heat transfer coefficients. In similar manner, the model uses expressions for Sherwood numbers for laminar and turbulent flow using a thermal Grasholf number, $\mathrm{Gr}=l^{3} \frac{\left(\mathrm{T}_{\text {wall }}-\mathrm{T}_{\mathrm{bulk}}\right)}{\left(\mu_{M} / \rho_{m}\right)^{2} \mathrm{~T}_{b u l k}} g$ Thus for laminar flow $\left(\mathrm{Gr}<10^{9}\right)$, the Sherwood number is

$$
\mathrm{Sh}=\frac{\mathrm{k}_{c} l}{\mathrm{D}_{\mathrm{I}_{2}}}=0.59(\mathrm{Gr} \mathrm{Sc})^{1 / 4}
$$

and for turbulent flow $(109<\mathrm{Gr}<1012)$.

$$
\mathrm{Sh}=\frac{\mathrm{k}_{\mathrm{c}} \mathrm{l}}{\mathrm{D}_{\mathrm{I}_{2}}}=0.13(\mathrm{Gr} \mathrm{Sc})^{1 / 3}
$$

where $S c=S c h m i d t$ number $=\mu_{M} / o_{M} D_{I_{2}}$

and $. \quad l=$ length of the wall

$k_{c}=$ mass transfer coefficient.

A combination of the two Sherwuvel umiliers is used to compute the actual Sherwood number. Since the turbulence in most cases occurs around $10 \mathrm{ft}$ from the top of the wa11, a weighted average was used.

$$
\operatorname{Sh}\left(\text { overa11) }=\frac{\ell-10}{\ell} \operatorname{Sh}(\text { turbulent })+\frac{10}{\ell} \operatorname{Sh}(\text { laminar })\right. \text {. }
$$

To convert the mass transfer cnefficient into a deposition lambda $\left(\lambda_{i j}\right)$ is a simple step. Thus,

$$
\lambda_{i j}(k)=k_{c}(k) A(k) / V(k)
$$

where $A(k)$ and $V(k)$ are surface area and volume of compartment $k$, respectively.

Another natural deposition process of interest is the settling of particulates. This involves a calculation of terminal settling velocities, $V_{S}$, assuming spherical, unit density particles. 


$$
d^{2}\left(p_{p}-p_{m}\right) g / 18 u_{m}=v_{s}
$$

Particle diameters used were considered as functions of time. Hilliard and Coleman (5) report that the settling velocities decrease with time after release. In CORRAL it was decided to use their data and assign an early particle diameter and a late particle diameter ("several hours"' later = $3 \mathrm{hrs}$ ) and linearly interpolate between them. After 3 hrs., the particle size was kept constant at the late value. To get the natural deposition lambda for particulates use

$$
\lambda=v_{s} \frac{A(f l o o r \text { area })}{V(\text { compartment volume })}
$$

Spray Removal. The spray removal model of $\mathrm{I}_{2}$ by boric acid and caustic sprays used in CORRAL combines a gas phase mass transfer coefficient, a drop-gas interfacial equilibrium distribution coefficient and a stagnant liquid film mass transfer coefficient. The expression for the spray lambda is given by

where

$$
\lambda=\frac{F H}{V}\left[1-\exp -\left(6 \frac{k_{g} t_{e}}{d\left(H+k_{g} / k_{\ell}\right)}\right)\right] / H \text { at equilibrium) }
$$

$$
\begin{aligned}
F & =\text { spray flow rate } \\
H & =\text { cquilibrium distribution coefficient } \\
& \quad\left(\mathrm{C}_{\mathrm{g}}=\mathrm{C}_{\ell} / \mathrm{H}_{\mathrm{j}} \text { at equil. }\right) \\
\mathrm{V}= & \text { spray compartment volume } \\
\mathrm{d} & =\text { spray diameter } \\
\mathrm{t} & =\text { drop residence time - height of fall/terminal veloc1ty }
\end{aligned}
$$

and the gas mass transfer coefficient, $k_{g}$, is given by Ranz and Marshall (11) as

and

$$
k_{g}=\frac{D_{2}}{d}\left\{2.0+0.60 \operatorname{Re}^{1 / 2} \mathrm{Sc}^{1 / 3}\right\}
$$

$$
k_{l}=\frac{2 \pi^{2} D_{l}}{3 d}, D_{l}=I_{2} \text { diffusivity in liquid. }
$$

The latter is the Griffiths model discussed by Postma. (6) Incorporating the latter is a more conservative approach when $\mathrm{k}_{\mathrm{g}} / \mathrm{k}_{\ell} \geq 5 \mathrm{H}$. The terminal velocities of the falling drops are found by matching the velocity independent dimensionless number

$$
f_{D} R c^{2}=4 \rho_{M}\left(\rho_{L}-\rho_{M}\right) d^{3} g / 3_{\mu_{M}}{ }^{2}
$$

with the appropriate range of Reynolds number Re. For spray drops the range of $\operatorname{Re}$ is $10-700$. For $10<\operatorname{Re}=100, \mathrm{f}_{\mathrm{D}} \operatorname{Re}^{2}=15.71 \mathrm{Re} 1.417$, and for $100=$ Re. $<700, \mathrm{FDRe}^{2}=6.477 \mathrm{Re}^{1.609}$ (Reference 2). 
Spray lambdas for removal of particles follow the equation:

$$
\lambda=\frac{3 F E h}{2 V d}
$$

where

$$
\begin{aligned}
& \mathbf{F}=\text { spray flow rate } \\
& \mathbf{h}=\text { spray fall height } \\
& \mathbf{d}=\text { spray diameter } \\
& \mathbf{V}=\text { compartment volume } \\
& \mathbf{E}=\text { spray collection efficiency. }
\end{aligned}
$$

In CORRAL empirical results from CSE data are used to predict E. Apparently the efficiency is a function of a normalized liquid volume sprayed (total volume sprayed/total compartment volume - Ft/V). Figure 4 shows the CSE data, and the curve in this figure was used to compute drop collection efficiencies in CORRAL. The diffusiophoresis was subtracted from the efficiency and the following expressions were fit to the remaining curve. To make these relationships apply to a spray lambda

$$
\begin{aligned}
& 0-\frac{\mathrm{Ft} / \mathrm{V}}{0.002} \\
& .002-.0193 \\
& .0193 \\
& \begin{array}{l}
\frac{E}{E=-15.825(\mathrm{Ft} / \mathrm{V})+.055} \\
E=\quad .04125-(.08626+42.68(\mathrm{Ft} / \mathrm{V}))^{1 / 2} / 21.34 \\
E=\quad .0015
\end{array}
\end{aligned}
$$

with multiple sprays being used at various times, the quantity $\mathrm{Ft} / \mathrm{V}$ is now the sum $\Sigma F_{i} t_{i} / V$ for any one release of particles. Each release of particles would have its own spray aging relationship, and at this time no simple means of typing sequential release together into one relationship seems possible. Only when particle size distributions are known throughout a spray aging process will sequential releases be able to be tied together:

It should be noted that in CORRAL, no spray cutoff is used at $C(t) / C(0)=.02$; spray aging is used. in its place.

I2 Equilibrium. When airborne molecular lodine is depleted by efther sprays or natural deposition, the depletion rate becomes independent of the two above mechanisms when the concentration falls below about 1 percent of the initial value (a conservative estimate, i.e., a lower value is less conservative( $(8)$ ). At concentrations below this level, an apparent equilibrium situation exists" where the concentrations in liquid and gas phases are related by an equilibrium distribution constant, $H=C_{p} / C_{g}$. $H$ is a function of time (probably due to slow liquid phase chemical reaction) and has been experimentally determined. In program CORRAL it has bee posstble to incorporate $H=H(t)$ when equilibrium conditions exist.

To get the equilibrium described quantitatively, an equivalent lambda for depletion of gas phase $I_{2}$ had to be developed. Since the value of $\mathrm{H}$ increases with increasing time, the gas phase is being depleted as. time goes on. To get this equivalent lambda, we can write a mass balance for $I_{2}$. If $C_{g o}$ is the initial airbornc concentration, then

$$
\mathrm{C}_{\text {go }} \mathrm{v}_{\mathrm{g}}=\mathrm{C}_{\ell} \mathrm{v}_{\ell}+\mathrm{C}_{\mathrm{g}} \mathrm{v}_{\mathrm{g}} \text { : }
$$




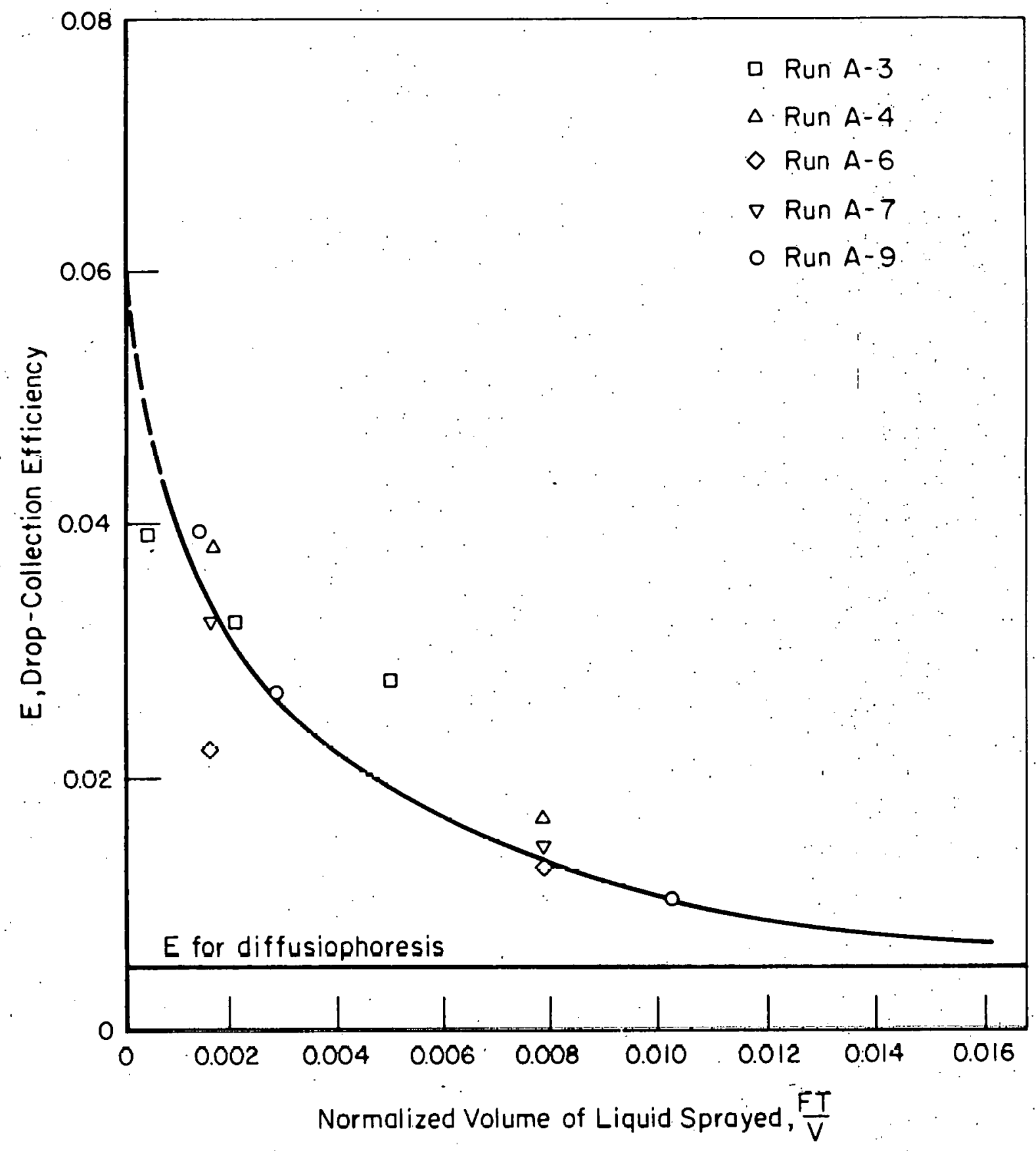

FIGURE 4. DROP-COLLECTION EFFICIENCY AS A FUNCTION OF LIQUID VOLUME SPRAYED

Points are plotted at mid-times of spray periods (fresh spray only). 
or

$$
\frac{c_{g}}{c_{g \circ}}=\frac{c_{g} v_{g}}{c_{l} v_{l}+c_{g} v_{g}}=\frac{1}{\frac{c_{l} v_{l}}{c_{g} v_{g}}+1}=\frac{1}{\frac{H_{l}}{v_{g}}+1} .
$$

Then for $H=H(t)$, we can write the removal rate of $I_{2}$ by

$$
\begin{aligned}
& \mathrm{d} \frac{\mathrm{C}_{\mathrm{g}} / \mathrm{C}_{\mathrm{gO}}}{\mathrm{dt}}=-\frac{1}{\left(\mathrm{H} \frac{\mathrm{l}}{\mathrm{V}_{\mathrm{g}}}+1\right)^{2}} \cdot\left(\frac{\mathrm{l}}{\mathrm{V}}\right) \frac{\mathrm{dH}}{\mathrm{g} t} \text { where the equivalent lambda is } \\
& d \frac{c}{d t}=-\left\{\left(\frac{1}{H \frac{V_{l}}{V_{g}}+1}\right) \frac{v_{l}}{V_{g}} \frac{d H}{d t}\right\} d t=-\lambda d t
\end{aligned}
$$

Data shows that $\mathrm{H} \mathrm{V} / \mathrm{V}_{\mathrm{g}}>>1$ for boric acid and caustic solutions in equilibrium with $I_{2}$, so that

$$
\lambda=\frac{1}{\mathrm{H}} \frac{\mathrm{dH}}{\mathrm{dt}}
$$


Typical data for sprays are shown in Tables 2 and 3.

TABLE 2. EQUILIBRIUM DATA FOR I 2 WITH BORIC ACID SPRAYS (7)

\begin{tabular}{ccc}
\hline Time, min & $\mathrm{H}$ & $\mathrm{C}_{\mathrm{g}} / \mathrm{C}_{\mathrm{gO}}$ \\
\hline 0 & 2676 & .01 \\
100 & $1.5 \times 10^{4}$ & $1.8 \times 10^{-3}$ \\
500 & $4.0 \times 10^{4}$ & $6.75 \times 10^{-4}$ \\
1000 & $7.0 \times 10^{4}$ & $3.86 \times 10^{-4}$ \\
2000 & $1.5 \times 10^{+5}$ & $1.8 \times 10^{-4}$ \\
4000 & $5 \times 10^{+5}$ & $5.4 \times 10^{-5}$ \\
$\geq 7000$ & $1 \times 10^{6}$ & $2.7 \times 10^{-5}$ \\
\hline
\end{tabular}

TABLE 3. EQUILIBRIUM DATA FOR $I_{2}$ WITH CAUSTIC SPRAYS (7)

\begin{tabular}{ccc}
\hline Time, min & $\mathrm{H}$ & \multicolumn{1}{c}{$\mathrm{C}_{\mathrm{g}} / \mathrm{C}_{\mathrm{gO}}$} \\
\hline $0-100$ & 0 & .01 \\
$100-1000$ & $\left(\lambda=.095 \mathrm{H}^{-1)}\right.$ & \\
1000 & $7.0 \times 10^{4}$ & $3.86 \times 10^{-4}$ \\
2000 & $1.5 \times 105$ & $1.8 \times 10^{-4}$ \\
4000 & $5 \times 105$ & $5.4 \times 10^{-5}$ \\
$\geq 7000$ & $1 \times 106$ & $2.7 \times 10^{-5}$ \\
\hline
\end{tabular}

Intercompartmental Flow Rates. In two cases intercompartmental flow rates can be calculated. If circulation fans move air throughout the containment vessel or if boll-off occurs with steam evolution into one compartment, one can use these flow rates to provide a basis for estimating intercompartmental flows. In addition, natural convection driven by wallbulk gas temperature differences can be a major contributor to fiow rates. These rates can be estimated but with a high degree of uncertainty.

In this study, high flow rates have been used to eliminate mixing as a parameter. The flows for. PWR cases follow the schematic in Figure 5. Flow rates used were $Q_{1}=$ blow down steam rate and $Q_{2}=10$ PWR containment volumes per hour.

Multicompartment Containment Model - BWR

The multicompartment feature of code CORRAL was essential to estimating atmospheric source calculations from a BWR. A BWR containment 


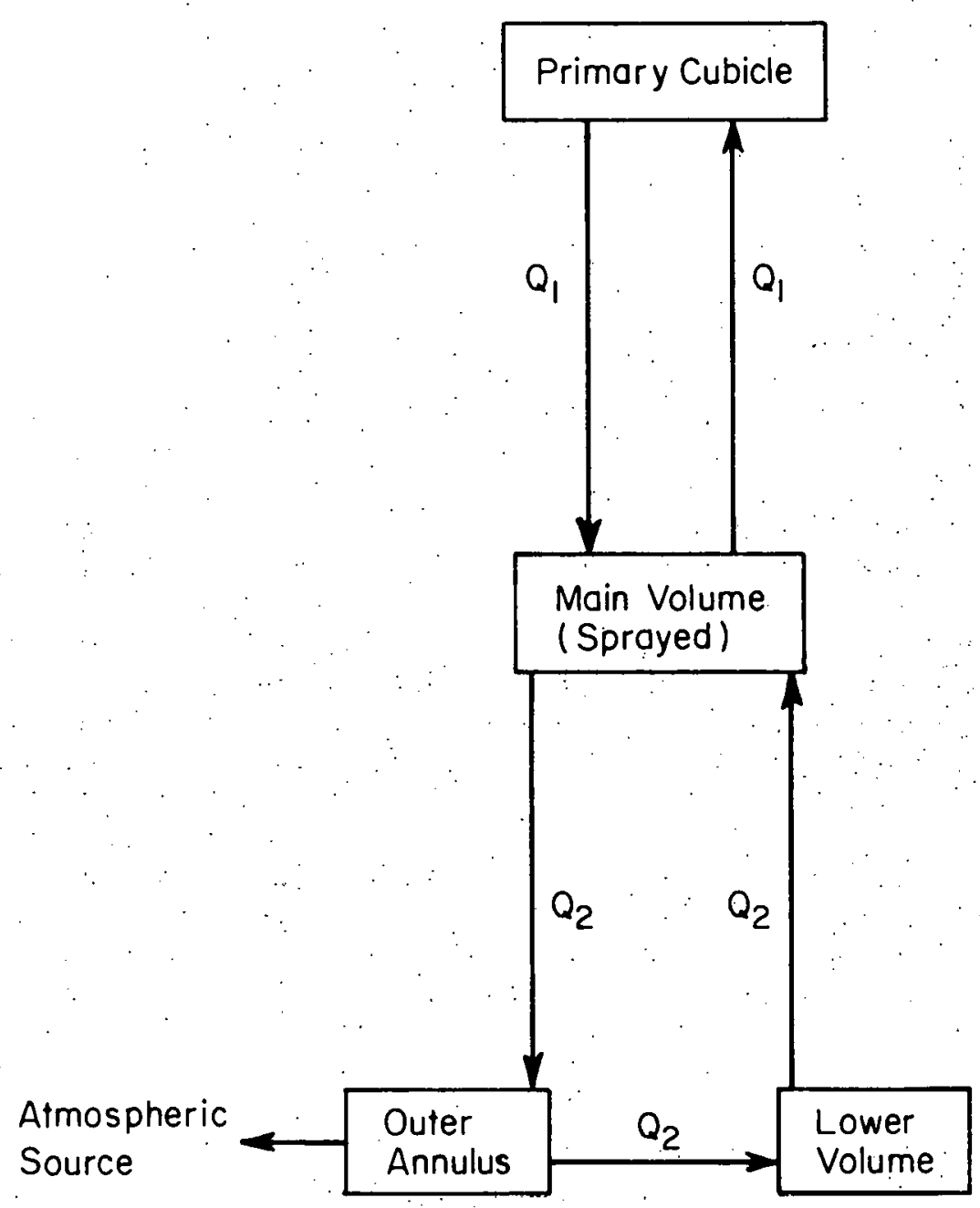

FIGURE 5. GAS FLOW FOR PWR CASES 
system is not a set of openly connected compartments like a PWR, where the whole containment system can be usually considered as "well mixed". The compartments of a BWR are usually closed to one-another and flows between them occur in complex ways during postulated accidents.

As many as six compartments are used in some BWR accident sequences: The first five are:

(1) The Drywe11 where natural deposition can occur.

(2) The Wetwell where pool scrubbing and natural deposition can occur.

(3) The Drywe11 annular gap where natural deposition can occur,

(4) The Reactor Building where natural deposition can occur.

(5) The Standby Gas Treatment System (a series of filters).

The sixth compartment used was a fict1tlous dumping ground for ground level atmospheric sources when elevated (stack) sources occurred simultaneously. The schematic flow diagram for BWR accidents is shown in Figure 6 .

Although the BWR containment model is rather specific, it still must be considered an approximate treatment of actual conditions. For example, pool scrubbing of vapor-phase fission products in the wetwell is modeled using a simple decontamination factor rather than a rigorous solution of the dynamic transport and absorption problem. In addition, the drywell annular air gap is used to simulate the entire lower region of the secondary containment building. For situations in which leakage from the primary containment boundry occurs directly from the drywell or wetwell steel shells, this provides an accurate description of the geometry and flow path to the refueling floor level of the secondary containment. For cases in which the leakage site is in one of the several sublevels of secondary containment (e.g., isolation valve failure), the model represents an approximation of the geometries and flow paths between these various leakage locations and the refueling floor level. However, the method described later for calculating fission product transport and deposition in the annular region is expected to overestimate rather than underestimate fission product concentrations that would reach the refueling building under such conditions. This is because the combination of longer residence time and deposition in the lower regions of secondary containment would usually be more effective than the decontamination factors predicted for the annulus.

Note in Figure 6 that potential releases of fission products directly to the atmosphere are indicated for all compartments. Release from the standby gas treatment system is the normal mode, and this would be an elevated release via the plant stack. All other potential releases would be at ground level. Direct releases from the main reactor (refueling) building could occur because of failure to isolate the building or because gas flow into the building during a particular accident might exceed the exhaust capacity of the standby gas treatment system blowers. Direct releases from the annulus (and/or lower secondary containment) could occur if high volume gas flow, caused by isolation fallure of a large penetration in primary containment, would result in structural failure: of the reactor building wall panels. This could also result from rupture of primary 


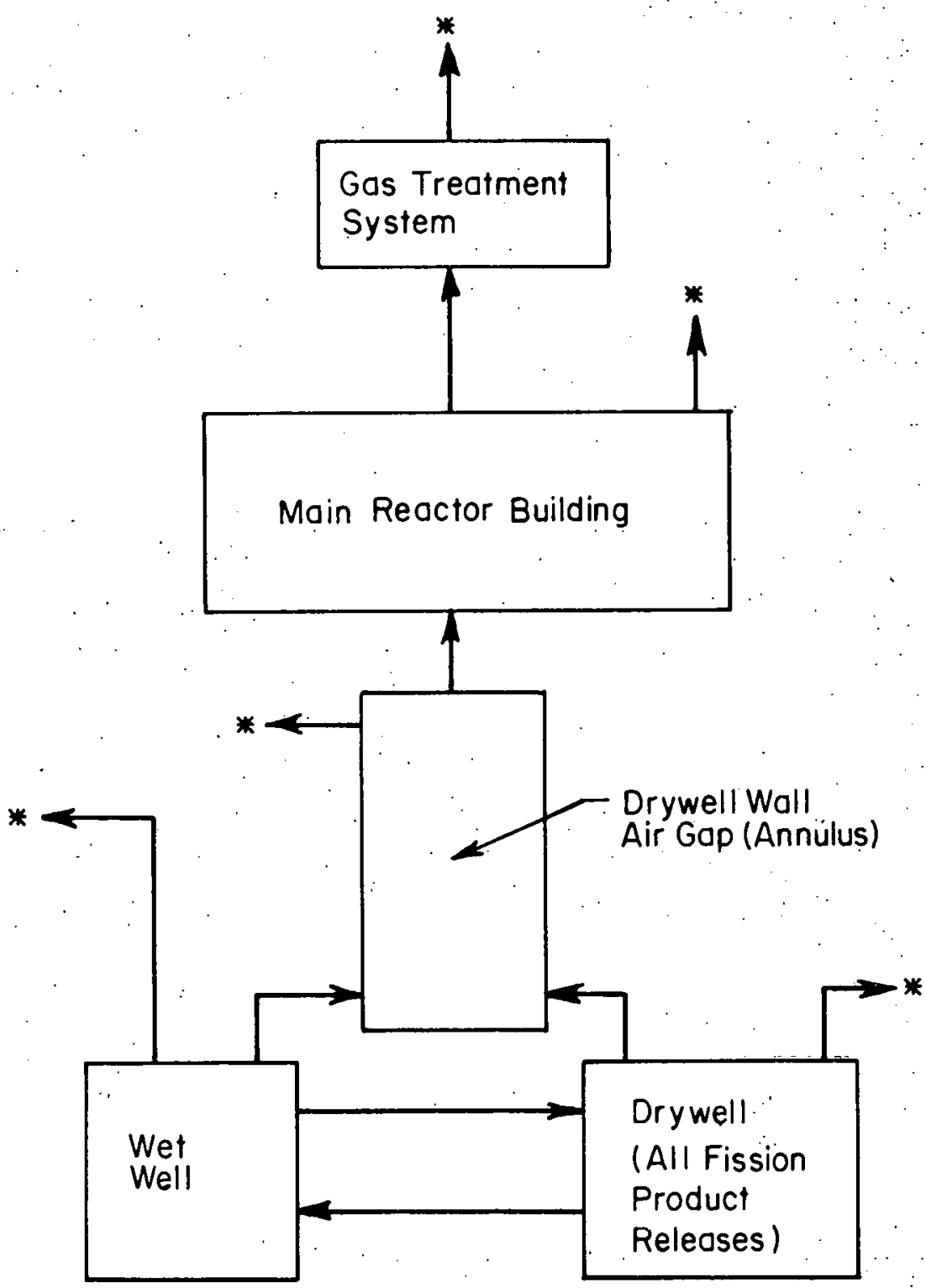

FIGURE 6. FLOW SCHEMATIC FOR A BWR - (*POSSIBLE ATMOSPHERIC SOUR CE) 
containment, provided the event does not cause failure of an outside wall in the sublevels of secondary containment. The alternative (i.e., structural failure of outside walls) could produce the direct release from either the drywe11 or wetwell compartments. In calculating such direct release cases, internal fission product removal is considered only for compartments up to and including the one from which the direct release occurs.

Natural deposition is the most common removal mechanism for fission products, although.it is not necessarily the most effective mechanism. Natural deposition of particulates occurs on horizontal surfaces in all large compartments just as in a PWR. Turbulent deposition of particulates and iodine in the drywe 11 annular air gap occur by different mechanisms to be discussed later. Natural deposition of iodine occurs on all surfaces with the rate controlled by natural convection discussed on page 17 . However, since the wall-bulk gas temperature-difference that drives the natural convection is highly variable in a BWR, translent heat transfer analyses are made to estimate this temperature-ditterence.

Natural Deposition - Effect of Heat Transfer from BWR Vessel Walls. The mass transfer coefficient for $I_{2}$ removal (see Equations 6 and 7 ), is proportional to the temperature-difference,

$$
\mathrm{T}_{\mathrm{wa} 11}-\mathrm{T}_{\mathrm{bu} 1 \mathrm{k}}=\Delta \mathrm{T}_{\mathrm{w}}
$$

raised to the $1 / 4$ or $1 / 3$ power. For an order of magnitude range in $\Delta \mathrm{T}_{\mathrm{W}}$, the mass transfer coefficient changes by only a factor of 2 , a relatively insignificant change. However, during rapid cooling of the drywell (depressurization), $\Delta \mathrm{T}_{\mathrm{W}}$ can span more than an order of magnitude for short durations. During rapid heating, the condensing heat transfer coefficient is large $\left(\mathrm{h}=150 \mathrm{Btu} / \mathrm{hr}, \mathrm{ft}^{2}, \mathrm{~F}\right)$ and a steady $\Delta \mathrm{T}_{\mathrm{W}}$ is rapidly reached. This is about $0.14 \mathrm{~F}$ in the drywe11. In cooling, the heat transfer coefficient from the steel (approximately one-inch thick) wall is 1 ow $(2-5 \mathrm{Btu} / \mathrm{hr}, \mathrm{ft}, \mathrm{F}$ ), and can lag behind the bulk gas temperature for some time. Neglecting any temperature gradient in the steel, for a sudden step change in bulk gas temperature, $\Delta \mathrm{T}_{\mathrm{S}}$, the temperature-difference, $\Delta \mathrm{T}_{\mathrm{W}}$, is given by

$$
\Delta \mathrm{T}_{\mathrm{w}}=\Delta \mathrm{T}_{\mathrm{s}} \exp \left(-\mathrm{ht} / \ell_{\rho c_{\mathrm{p}}}\right)
$$

where

$$
\begin{aligned}
h & =\text { heat transfer coefficient } \\
t & =\text { time after } \Delta \mathrm{T}_{s} \\
l & =\text { wall thickness } \\
p & =\text { wall mass density } \\
c_{p} & =\text { wall heat capacity (per unit mass) }
\end{aligned}
$$

If the temperature change is gradual, i.e., linear with respect to time. The temperature-difference, $\Delta \mathrm{T}_{\mathrm{w}}$, is now given by

$$
\Delta \mathrm{T}_{\mathrm{w}}=\left(\beta \ell_{\rho c_{\mathrm{p}}} / \mathrm{h}\right)\left[\exp -\left(\mathrm{ht} / \ell_{\rho c_{\mathrm{p}}}\right)-1\right]
$$

where $\beta$ is the linear bulk-gas cooiing rate, F/hr. Equations (34) and (35) are used to compute $\Delta \mathrm{T}_{\mathrm{w}}$ for various time intervals during cooling in the 
drywe 11 and wetwel1. Values of $h$ depend on gas velocities in the above compartments as we11 as the drywell annular air gap.

Little information could be readily obtained to estimate $\Delta \mathrm{T}_{\mathrm{w}}$ 's in the main reactor builidng. These would be highly dependent on positions in the building and the outside environment temperatures, as well as gas flow parameters from the reactor. To allow for some minimum natural deposition in the main building, $\Delta \mathrm{T}_{\mathrm{W}}=0.1 \mathrm{~F}$ was used. This would result in a natural deposition rate of $\lambda \stackrel{\cong}{=} 0.5 \mathrm{hr}^{-1}$ in the main reactor building for $\mathrm{I}_{2}$. This $\lambda$ is five times the gas displacement rate for the building under normal conditions (2,000 cfm through the Gas Treatment System).

Pool Scrubbing. In a number of BWR accident sequences gas flow occurs through the vent lines from the drywell to the wetwell water pool. The water pool occupies slightly over one-half the toroidal volume of the wetwel1 and is approximately.17-feet deep. Pool scrubbing is a major. decontamination mechanism. Some data exists on pool scrubbing, but comprehensive experimental studies on pool scrubbing in a BWR wetwell pool that include investigations of all parameters (a wide range of particle sizes, steam quality, pool temperatures, flow rates, $I_{2}$ concentrations, downcomer. L/D ratios, etc...) have not been reported. Applying such data, if available, would not have refined atmospheric source estimates greatly, because the available data show that scrubbing is fairly effective on the fission. products entering the pool. Also, trial calculations showed that of ten 30 percent or more of the available fission products in any sequence would escape the primary containment by other paths (such as through the drywell annular gap directly to the secondary containment system).

The best available data appears in a paper by Diffey, Rumary, et $a 1,(12)$ where $I_{2}$, methyl iodide; and $.06 \mu$ particles in a steam-air mixture were pool scrubbed. The typical decontamination factors were 100 for $\mathrm{I}_{2}, 2$ for $\mathrm{CH}_{3} \mathrm{I}$, and $50-100$ for the $.06 \mu$ particles with 90 percent steam-air mixtures (higher steam fractions give better decontamination). For CORRAL-BWR cases, the values used are 100 for both $I_{2}$ and particles, provided the bulk gas is mostly steam and condensation is expected in the pool. A decontamination factor of $1.0^{\text {is }}$ always used for methyl iodide and the noble gases.

Even though the BWR accident particles are assumed to be 5-15 $\mu$, or much more massive than those studied above, the scrubbing of particles is largely due to diffusiophoresie (condensing steam on the bubble wall carries particles), and therefore largely.independent of particle size. However, larger particles would have more boundary layer penetration inertia in a rapidly circulating bubble and this should then further justify the choice of $\mathrm{DF}=100$ for particles, rather than the lower DF of 50 .

Standby Gas Treatment System - (SGTS). The SGTS in a typical BWR is a set of two parallel filter trains upstream from three exhaust fans that releases filtered secondary containment building air at an elevated level via a stack. However, under accident conditions only one of the 
filter trains would normally be used, the other being held in reserve. The SGTS keeps the building at subatmospheric pressures to minimize ground level leaks. Under normal conditions the flow rate through the system is about $2,000 \mathrm{cfm}$ and the filter trains are rated to remove

- $99.97 \%$ of $0.3 \mu$ diameter particles (high-efficiency filter),

- $99.9 \%$ of $I_{2}$, (impregnated charcoal filter),

- $85 \%$ of methyl iodide, (impregnated charcoal filter),

at all flow rates up to some maximum capacity, about $10,000 \mathrm{cfm}$. Sources in excess of the maximum would over-pressurize the building and create a ground level atmospheric suurce.

High efficiency filters receive maximum penetration from $0.3 \mu$ particles. Both larger and smaller particles are more efficiently trapped. Therefore, a $99.99 \%$ efficiency was conservatively adopted for al1 particles $(D F=10,000)$, tor use in CORRAL-BWR calculations. The duvve tfficiencies for $\mathrm{I}_{2}$ and $\mathrm{CH}_{3} \mathrm{I}$ are used in the calculations for flow through the charcoal filters for all cases, except that CORRAL is programmed to identify the filter loading of $I_{2}$ to discover possible overheating, at which time the filtration efficiencies for $\mathrm{I}_{2}$ and $\mathrm{CH}_{3} \mathrm{I}$ would decrease significantly. (See main report for description of the overheating criteria.)

Natural Deposition in the Drywe11 Annular Airspace. The drywell shell is surrounded by a two-inch air gap between the steel shell and the concrete shield containing the shel1. Normal leakage across the shell or rupture of the she11 can result in transport through the air gap with an exit into the secondary containment. For analys is purposes, the drywell leakage point is considered to occur near the base, in the vicinity of the eight vent lines leading to the wetwell. The exit point is at the top flange assembly. The flow path of gases from the shell rupture is thus around the spherical part of the she11, longitudinally through the cylindrical upper annulus and out the flange.

The annular region cannot be modeled like the well mixed compartments with deposition on the walls and/or floor. It is better described as plug flow along a cylindrical annulus with mass transfer to the walls. A simple first order differentail equation defines a mass transfer coefficient, $k$, that can be estimated from known correlations for $I_{2}$ transfer. For particles, $k$ can be estimated from particle deposition data from moving gas streams with more difficulty and uncertainty. The differential equation for transfer to the walls of an annular slit is:

$$
\frac{d C}{\left(C-C_{w}\right)}=-\left(\frac{2 k}{U \Delta r}\right) \cdot d x
$$

where

$$
\begin{aligned}
C & =\text { the concentration of the transferring substance } \\
C_{W} & =\text { wall concentration } \\
\mathrm{J} & =\text { axial plug flow velocity } \\
\Delta \mathbf{r} & =\text { annulus width } \\
\mathbf{x} & =\text { axial distance } \\
\mathrm{k} & =\text { mass transfer coefficient. }
\end{aligned}
$$


If $C_{W}=0$, Equation (36) integrates for $0 \leq x \leq l$ to

$$
\frac{c}{C(x=0)}=\exp \left[-\left(\frac{2 k}{\underline{U} \Delta r}\right) l\right]
$$

assuming an average axial velocity, $\underline{U}$,

where

$$
\underline{\mathrm{U}}=\frac{\mathrm{Q}}{\mathrm{A} \mathrm{av}}
$$

$$
\begin{aligned}
A_{a v} & =\Delta r \int_{0}^{l} \pi r d x / l, \text { average annulus cross section, and } \\
Q & =\text { volumetric flow rate } .
\end{aligned}
$$

For the annular gap described earlier for a typical BWR, equation (37) above becomes

$$
\frac{C .}{C(x=0)}=\exp (-1200 \mathrm{k} / \underline{U})
$$

The assumption that $C_{W}=0$ for both particulates and $I_{2}$ is reasonable for most conditions in the BWR accident cases. Molecular $\mathrm{I}_{2}$ has been experimentally verified to have a high affinity for steel and paint surfaces. $(5,13)$ Normal1y the overall mass transfer coefficient for $I_{2}$ would be

$$
\mathrm{k}^{-1}=\mathrm{k}_{\mathrm{w}}^{-1}+\mathrm{k}_{\mathrm{g}}^{-1}
$$

where $\mathrm{k}_{\mathrm{g}}$ is the boundary layer coefficient and $\mathrm{k}_{\mathrm{w}}$ is a first order rate constant for the surface reaction. (13) The value of $k_{W}$ is difficult to predict for the annulus since it is a function of temperature, surface composition, surface roughness, $\mathrm{I}_{2}$ concentration, and vapor pressure. Thue, for the drywell annı1 11s the surface was assumed, to be a "perfect sink" for $I_{2}$ with no desorption occurring.

The gas phase mass transfer coefficients for $\mathrm{I}_{2}$ are estimated using the following analogies from heat transfer correlations. (11) For we 11 developed turbulent flow $(\operatorname{Re}>20,000)$

$$
\mathrm{Sh}=\frac{\mathrm{k} 4 \mathrm{Rh}}{\mathrm{D}_{\mathrm{I}_{2}}}=0.026 \cdot \mathrm{Re}^{0.8} \mathrm{Sc}^{1 / 3}
$$

and for laminar isothermal flow $(\operatorname{Re}<2,100)$

$$
S h=1.86(\operatorname{Re} \cdot S c \cdot 4 R h / \ell)^{1 / 3}
$$

where

$$
\operatorname{Re}=\operatorname{Reynolds} \text { number }=\frac{\rho U(4 R h)}{\mu}
$$




$$
\begin{aligned}
\mathrm{Rh} & =\text { hydraulic radius } \\
& =\frac{\text { flow cross sectional area }}{\text { wetted parameter }} \\
& =\Delta \mathrm{r} / 2 \text { for the annulus }
\end{aligned}
$$

The transition region, $2100<\operatorname{Re}<20,000$, is not well understood and Equation (40) could overestimate the mass transfer coefficient by a factor of 3-5 at $R e=2100$. This error is offset by the non-smooth nature of the annular gap, which could also cause an underestimation of $k$ for high Reynolds numbers. For BWR cases encountered, the Reynolds number ranges from the laminar region to about 30,000. The maximum DF's occur at $\operatorname{Re}=0$ and $R e=2101$ ( $D F \div 10)$. A cutoff of $D F=100$ maximum for $I_{2}$ is assumed in CORRAL-BWR calculations for the annular gap. This is done because of the possibility of desorption or saturation of the annular suface.

The behavior of particulates is more difficult to predict because deposition velocities from moving gas streams are a function of particle size as well as gas velocity. Sehmel(14) has recently publișhed experimental data that allows an estimation of particle deposition in the annular gap. The deposition velocity (or mass transfer coefficient) is highly affected by gravity. Most of Sehmel's data is for deposition on floor. and ceilings, and the deposition in the drywell is on an essentially vertical wall. Wall deposition velocities are closest to floor deposition velocities, but are slightly lower for inertial particles (usually $\geq 0.1 \mu$ ). For these inertial particles, Brownian diffusion is nil, so $k=0$ has been assigned. ( $D F=1$ for $\operatorname{Re}<2100$ for all particles). Only the largest of the 5-15 $\mu$ particles have a significant turbulent deposition velocity.

An emperical fit of Sehmel's data is possible for $k=k$ ( $\left.\underline{U}, d_{p}\right)$, but he has only two $\underline{U}$ values for vertical wall deposition. For this reason, only a first order approximation can be made for $k$. This also eliminates major overhaul of CORRAL̈'s matrix computations to incorporate a new set of variables. The ratio $\mathrm{k} / \underline{\mathrm{U}}=1 / 300=$ constant for $a 11 \mathrm{k}$ and $\underline{U}$ for a particle size midway between 10 and $15 \mu$. Tabie 4 . shows the wide range of particle $D F ' s$ versus Reynolds number.

TABLE 4. DF VERSUS PARTICLE SIZE AND REYNOLDS NUMBER IN DRYWFTTI. ANNITITAR GAP

\begin{tabular}{rccc}
\hline$d_{p}, \mu$ & $D F(R e \leq 2100)$ & $D F(R e=2100)$ & $D F(F e=30,000)$ \\
\hline & 1.0 & 1.0 & 1.0 \\
10 & 1.0 & 1.1 & 1.1 \\
15 & 1.0 & $4.4 \times 10^{5}$ & $2.2 \times 10^{4}$ \\
\hline
\end{tabular}


To be conservative, an upper limit of $D F=100$ seems more reasonable to assign to $d_{p}=15 \mu$ (for $\left.k / \underline{U}=1 / 300, D F=27\right)$. With this upper limit, the following emperical equation fits the particle range:

$$
D F=1.0+0.1 \frac{d}{5}-5^{9.95}
$$

for $10 \leq d p \leq 15 \mu$ particles and $D F=1.0$ for $d_{p}<10 \mu$. Integrating Equation $(4 \overline{2})$ above over the aging process of the particles as they settle out in 3 hours (see page 18$)$, produces $D F(a v g)=10.0$. Since the age of airborne particles undergoing natural deposition is important longer than the 3 hours time period (approximately two of these periods), the average $D F=5.5$. This value was used in CORRAL-BWR calculations for all particles passing through the annular gap for $R e=2100$. It is a conservative number because approximately 90 percent of the mass of particles released is $=10 \mu$ in the CSE data and also in the CORRAL calculations. The mass average particle is $13.5 \mu$ which has a DF - 21 . Thus picking $\mathrm{DF}=5.5$ over-estimates early atmospheric sources and under-estimates additional sources on a long time basis. Certainly on a mass average basis, $D F=5.5$ is conservative.

\section{Computer Code CORRAL}

The multicompartment containment model was programmed with Fortran V for use on a Univac 1108. The program incorporates the models for fission product removal discussed in the previous section. Figure 7 shows the basic flow chart for CORRAL. A summary of each of the five flow chart sections follows.

\section{Input Parameters}

\section{Constants}

a. Core fractions for gap, meit, stéälu expluslun and vaporization releases.

b. Numbers of compartments.

c. Volumes, wall areas, floor areas, heights of each compartment.

d. Spray parameters (flow rates, drop sizes, fall heights, equilibrium conditions for $\mathrm{I}_{2}$ removal, $\mathrm{I}_{2}$ distribution coefficient).

e." Times of all events.

f. Compartment filter decontamination rates.

g. Fractions of compartments released during a puff release.

\section{Variables (with time)}

a. Pressure, temperature, and water vapor content of each compartment. Temperature difference between bulk gas and walls.

b. Flow rates between compartments.

c. Decontamination factors between compartments. 
Section 1

Section 2

Section 3

Section 4

Section 5

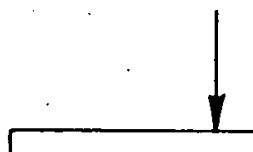

Input Parameters

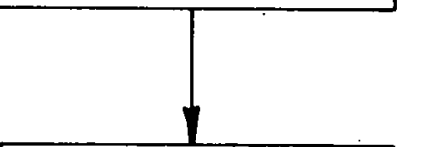

Initial Conditions

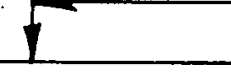

Compute Properties, Rate Constants, etc.

Exact Solution of Coupled

First-Order Differential Equations

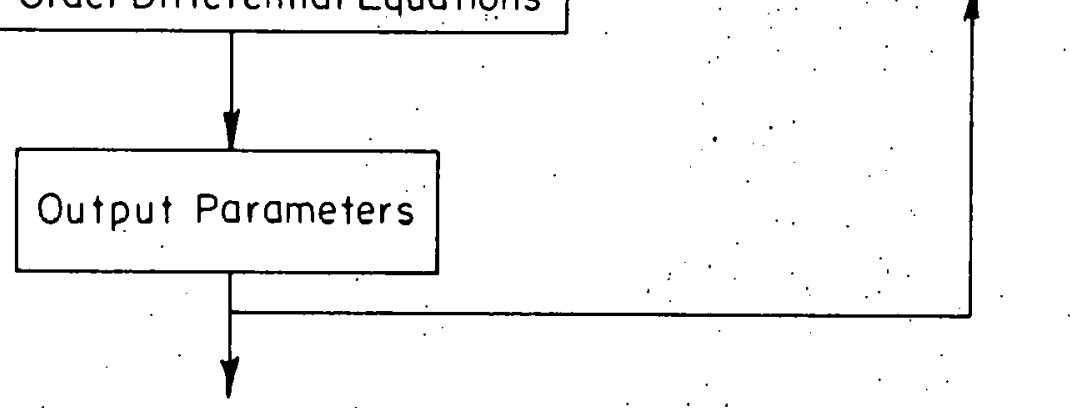

FIGURE 7. COMPUTER CODE CORRAL FLOW DIAGRAM 
d. Particle sizes:

e. Leak rates to atmosphere and leak DF's (decontamination factors).

2. Initial Consitions

a. All concentrations set equal to zero at $t=0$ except gap release concentrations in first compartment.

b. Spray set to operate in main compartment (PWR).

c. All amounts released and DRF's (dose reduction factors) set equal to zero. A zero DRF means that nothing has been released.

3. Computation of Properties and Removal Rates

a. Pressure, temperature, and water vapor content and $T(b u 1 k)$ $\mathrm{T}$ (wa11) by parabolic interpolation.

b. Intercompartment flow rates and decontamination factors and leak rates and respective DF's by parabolic interpolation.

c. Particle sizes by linear interpolation.

d. Gas phase viscosities and $I_{2}$ diffusivities and Schmidt numbers.

e. Mass transfer Grashof number's and corresponding depositing rates.

f. Particles settling velocities and their natural deposition.

g. Spray lambdas for particles.

h. Terminal spray velocities, gas phase mass transfer coefficient, liquid phase mass transfer coefficient, and spray lambdas.

i. $I_{2}$ equilibrium equivalent lambdas (if needed).

j. Overa11 lambdas.

\section{Solution of Differential Equations}

The solution of the differential equations is discussed in the previous section. To properly age the continuous releases, it was necessary to divide these releases into discrete impulse releases. The melt release was divided into ten equally spaced and sized releases, each independent age wise from the other nine. The vaporization release (released at an exponentially decaying rate) was divided into 20 impulse releases, each successive release at an exponentially lower value than the first. The sum of the first ten releases equals $1 / 2$ the total release, and the remaining ten equals the remaining $1 / 2$. The duration of the period of the first ton ic one half-life. The duration of the second ten should be three half-lives for a reasonable approximation of an exponential decay.

Thus the total number of differential equations solved (one each for particulates; organic iodides, and $\left.I_{2}\right)$ for any time step is $(N=$ number of compartments) 


$\begin{array}{rr}\text { GAP RELEASE } & 3 \mathrm{~N} \text { equations } \\ \text { EXPLOSION RELEASE } & 3 \mathrm{~N} \\ \text { MELT RELEASE } & 30 \mathrm{~N} \\ \text { VAPORIZATION RELEASE } & \frac{60 \mathrm{~N}}{96 \mathrm{~N}} \text { equations }\end{array}$

The accuracy of the output depends on the rate of change of the rate coefficients, so short time steps would be desirable immediately after each discrete release (aging is rapid at first, especially if sprays are on). Long time steps are sufficient for old releases.

5. Output Variables

a. Airborne contained fractions released at time, $t$.

1. For each release: $I_{2}$, organic iodides, particulates .

2. For each compartment for each release: $I_{2}$; organic iodides, particulates, at time, $t$.

b. Escaped fractions released (for each release: $I_{2}$, organic iodides, particulates, at time, $t$ ).

c. Escape fractions of the core for any desired iosotope.

d. Dose reduction factor for each release $\left(\mathrm{I}_{2}\right.$ and particulates) at time, $t$.

e. Overall dose reduction factor $\left(\mathrm{I}_{2}\right.$ and particulates) at time, $t$.

f. Total fraction of core iodine escaped and core particulates escaped up to time, $t$. 


\section{$\underline{\text { References }}$}

1. McCormack, J. D., R. K. Hilliard, and A. K. Postma, "Removal of Airborne Fission Products by Recirculating Filter Systems in the Containment Systems Experiment"; BNWL-1587, Battelle-Northwest, Richland, Washington (June 1971).

2. Postma, A. K., and R. K. Hilliard, "Absorption of Methyl Iodide by Sodium Thiosuifate Sprays", ANS Trans. 12; p 898-899 (November. 1969).

3. Knudsen, J. G., and R. K. Hilliard, "Fission Product Transport by Natural Processes in Containment Vesse1s", BNWL-943, BattelleNorthwest, Richland (1969).

4. Hales, J. M., T. W. Horst, and L. C. Schwendiman, "Aerosol Transport In a Condensing-Steam Boundary Layer", BNWL-1125, Battelle-Northwest, Richland, Washington (1970).

5. Hilliard, R. K., and L. F. Coleman, "Natural Transport Effects on Fission Product Behavior in the Containment Systems Experiment", BNWL-1457, Battelle-Northwest, Richland, Washington (1970).

6. Postma, A. K., and.W. F. Pasedag, "A Review of Mathematical Models for Predicting Spray Removal of Fission Products in Reactor Containment Vesse1s', BNWL-B-268, Battelle-Northwest, Richland, Washington (1973).

7. Postma, A. K., L. F. Coleman, and R. K. Hilliard, "Iodine Removal from Containment Atmospheres by Boric Acid Spray", Report No. BNP-100; Battelle-Northwest, Richland, Washington (1970):

8. Hilliard, R. K., A. K. Postma, et al., "Removal of Iodine and Particles by Sprays in the Containment System Experiment", Nuclear Technology, 10, pp 499-519 (1971).

9. Reactor Physics Quarterly Report, April-June 1969, BNWL-1150, Battelle-Northwest, Richland, Washington (1969) (B. H. Duane; pp 2.5-2.7).

10. Knudsen, J. G., "Properties of Air-Steam Mixtures Containing Small Amounts of Iodine", BNWL-1326, Battelle-Northwest (1970).

11. Bird, R. B., W. E. Stewart, and E. N. Lightfoot, "Transport Phenomena", John Wiley and Sons, N. Y. (1960).

12. Diffey, H. R., C. H. Rumary, M. J. S. Smith and R. A. Stinchcombe (AERE, Harwe11, England), "Iodine Cleanup in a Steam Suppression System", CONF-650407 (Vo1 2), Internation Symposium on Fission Product Release and Transport under Accident Conditions, Oak Ridge, Tenn, pp 776-804 (April 1965). 


\section{References (Continued)}

13. Rosenberg, H. S., J. M. Genco, and D. L. Morrison, "Fission-Product Deposition and its Enhancement under Reactor Accident Conditions: Deposition on Containment-System Surfaces", BMI-1865, BattelleColumbus (May 1.969.).

14. Sehme1, G. A., "Particle Eddy Diffusivities and. Deposition Velocities for Isothermal Flow and Smooth Surfaces", Aerosol Science 4, PP 125-139 (1973). 


\section{DISTRIBUTION}

No. of

Copies

OFFSITE

$1 \quad$ Battelle Columbus

505 King Avenue

Columbus, Ohio 43201

R. L. Ritzman

1 Office of Regulation

U.S. Atomic Energy Commission

Germantown, Maryland 20767

L. N. Rib

2 Office of Regulation

U.S. Atomic Energy Commission Washington, D.C. 20845

W. F. Pasedag

R. W. Zavadoski

$1 \quad$ Massachusetts Institute of Technology Cambridge, Massachusetts 02139

N. C. Rasmussen

1 AEC Technical Information Center

ONSITE

$1 \quad$ HEDL

R. K. Hilliard

45 Battelle-Northwest

N. E. Carter

D. L. Condotta/R. D. Widrig

J. J. Fuquay

B. M. Johnson

D. L. Lessor

P. C. Owzarski(15)

L. T. Pederson

A. M. Platt

A. K. Postma (15)

D. L. Reid

L. C. Schwendiman

G. A. Sehmel

C. L. Simpson

Technical Information Files(3)

Technical Publications 